\title{
A Critical Cell-Intrinsic Role for Serum Response Factor in Glial Specification in the CNS
}

\author{
Paul P. Y. Lu and Narendrakumar Ramanan \\ Department of Anatomy and Neurobiology, Washington University School of Medicine, St. Louis, Missouri 63110
}

Astrocytes and oligodendrocytes play crucial roles in nearly every facet of nervous system development and function, including neuronal migration, synaptogenesis, synaptic plasticity, and myelination. Previous studies have widely characterized the signaling pathways important for astrocyte differentiation and unveiled a number of transcription factors that guide oligodendrocyte differentiation in the CNS. However, the identities of the transcription factors critical for astrocyte specification in the brain remain unknown. Here we show that deletion of the stimulus-dependent transcription factor, serum response factor (SRF), in neural precursor cells (NPCs) (Srf-NestincK0) results in nearly $60 \%$ loss in astrocytes and 50\% loss in oligodendrocyte precursors at birth. Cultured SRF-deficient NPCs exhibited normal growth rate and capacity to self-renew. However, SRF-deficient NPCs generated fewer astrocytes and oligodendrocytes in response to several lineage-specific differentiation factors. These deficits in glial differentiation were rescued by ectopic expression of wild-type SRF in SRF-deficient NPCs. Interestingly, ectopic expression of a constitutively active SRF (SRF-VP16) in NPCs augmented astrocyte differentiation in the presence of pro-astrocytic factors. However, SRF-VP16 expression in NPCs had an inhibitory effect on oligodendrocyte differentiation. In contrast, mice carrying conditional deletion of SRF in developing forebrain neurons (Srf-NEX-cKO) did not exhibit any deficits in astrocytes in the brain. Together, our observations suggest that SRF plays a critical cell-autonomous role in NPCs to regulate astrocyte and oligodendrocyte specification in vivo and in vitro.

\section{Introduction}

Astrocytes play multiple critical roles in brain development and functioning (Barres, 2008), and abnormalities in astrocyte development have been implicated in neurological disorders, including epilepsy, neurodegenerative disorders, and brain tumors (Lobsiger and Cleveland, 2007; Oberheim et al., 2008). Oligodendrocytes are essential for myelination (Hirano, 1968; Emery, 2010), and dysregulated myelination causes multiple sclerosis and leukodystrophy (Emery, 2010). Elucidating the molecular mechanisms regulating astrocyte and oligodendrocyte development is critical to our understanding of how these mechanisms might go awry in these disorders.

The onset of astrogliogenesis begins toward the end of neurogenesis and is regulated by several ligand-receptor complexes (Okano and Temple, 2009; Freeman, 2010). Widely studied cytokines among them include ciliary neurotrophic factor (CNTF), leukemia inhibitory factor (LIF), and cardiotrophin-1 (CT-1), which activate the Janus kinase (JAK)/signal transducer and activator of transcription (STAT) pathway to promote astrocyte differentiation (Johe et al., 1996; Bonni et al., 1997; Rajan and

Received Nov. 8, 2011; revised April 6, 2012; accepted April 25, 2012.

Author contributions: N.R. designed research; P.P.Y.L. performed research; P.P.Y.L. and N.R. analyzed data; P.P.Y.L. and N.R. wrote the paper.

This work was supported by Andrew B. and Virginia C. Craig Faculty Fellowship and Research Fund (N.R.). We thank Anna Oldenborg and Deanna Young for expert technical assistance. We thank members of the Ramanan laboratory for comments on this manuscript and useful discussions.

Correspondence should be addressed to Dr. Narendrakumar Ramanan, Department of Anatomy and Neurobiology, Washington University School of Medicine, 660 South Euclid Avenue, Campus Box 8108, St. Louis, M0 63110. E-mail:naren@pcg2.wustl.edu.

DOI:10.1523/JNEUROSCI.5633-11.2012

Copyright $\odot 2012$ the authors $\quad 0270-6474 / 12 / 328012-12 \$ 15.00 / 0$
McKay, 1998; Barnabé-Heider et al., 2005). Activation of bone morphogenetic protein 2/4 (BMP-2/4) signaling results in phosphorylation of SMAD (Sma and Mad-related proteins) transcription factors and their association with STAT3 to regulate expression of astrocyte-specific genes (Nakashima et al., 1999). However, perturbation of JAK/STAT signaling caused only a 45$70 \%$ reduction in astrocytes in vivo, suggesting contributions from other pathways. Notch is another widely studied pathway and gain-of-function studies have shown that Notch receptors play a permissive role in neural precursor cells (NPCs) to promote astrocyte differentiation (Morrison et al., 2000; Tanigaki et al., 2001; Gaiano and Fishell, 2002).

Transcriptional control of astrocyte specification has been studied mainly in the spinal cord. Sox 9 loss causes deficits in both astrocyte and oligodendrocyte generation (Stolt et al., 2003), whereas nuclear factor I-A/B and bHLH transcription factors, stem cell leukemia, and KLF15 (Krüppel-like factor 15) were found to be necessary and/or sufficient for astrocyte specification (Muroyama et al., 2005; Deneen et al., 2006; Fu et al., 2009). Oligodendrocyte specification occurs at late embryonic and early postnatal periods (Miller, 1996; Lee et al., 2000). Extracellular sonic hedgehog (Shh) signal in ventral telencephalon is necessary and sufficient for inducing commitment to oligodendrocyte precursors (Alberta et al., 2001; Tekki-Kessaris et al., 2001). Downstream to Shh signaling, two bHLH transcription factors, Olig1 and Olig2, are particularly important for oligodendrocyte development (Lu et al., 2001, 2002; Zhou et al., 2001; Zhou and Anderson, 2002). Other transcription factors, including Ying Yang 1 and members of Sox family of transcription factors, including Sox9, Sox10, and Sox17, play critical roles in oligodendrocyte 
specification (Stolt et al., 2002, 2003; Sohn et al., 2006; He et al., 2007).

Serum response factor (SRF) is a stimulus-dependent transcription factor required for differentiation and development of several different cell types, including keratinocytes, cardiac, and smooth muscle cells (Miano et al., 2004; Parlakian et al., 2004; Niu et al., 2005; Verdoni et al., 2010). Within the CNS, SRF regulates axon growth, tangential neuronal migration, activitydependent gene expression, synaptic plasticity, and learning and memory (Ramanan et al., 2005; Etkin et al., 2006; Knöll et al., 2006; Stern et al., 2009; Johnson et al., 2011; Lu and Ramanan, 2011). Here, we report a previously unidentified role for SRF in astrocyte and oligodendrocyte differentiation in the brain.

\section{Materials and Methods}

Animals. Srf ${ }^{\mathrm{f} / \mathrm{f}}$ mice (control) were maintained as a homozygous colony as described previously (Ramanan et al., 2005). The Srf-Nestin-cKO and Srf-NEX-cKO were generated as described previously (Lu and Ramanan, 2011) using a Nestin-Cre transgenic mouse line (Tronche et al., 1999) and a NEX-Cre line (Goebbels et al., 2006). The Srf ${ }^{\mathrm{f} /+} ; \mathrm{NesCre}$ double-heterozygous mice did not exhibit any discernible phenotype. Pups of either sex $(n=3-5)$ from at least two different litters were used in all experiments. All experiments were approved by the Animals Studies Committee, Division of Comparative Medicine, Washington University School of Medicine (St. Louis, MO).

Immunostaining, cell counts, and statistical analyses. Immunohistochemistry was performed as described previously (Ramanan et al., 2005). Primary antibodies used included the following: Aldh1L1 (1:100; catalog \#73-140; NeuroMab), S100 $\beta$ (1:1000; Sigma-Aldrich), GFAP (1:1000; catalog \#G145; Sigma-Aldrich), SRF (1:1500; Santa Cruz Biotechnology), Nestin (1:200; Developmental Studies Hybridoma Bank), Tuj1/ $\beta$ tubulin III (1:1000; Sigma-Aldrich), adenomatous polyposis coli (APC) (1:1000; Millipore), $\beta$-gal (1:1500; Aves Lab), O4 (1:750; Millipore), Olig2 (1:1000; Sigma-Aldrich), Olig1 (1:50; NeuroMab), activatedCaspase 3 (1:1500; Millipore), Sox2 (1:100; Santa Cruz Biotechnology), and platelet-derived growth factor receptor $\alpha$ (PDGFR $\alpha)$ (1:750; Thermo Fisher Scientific). Secondary antibodies included the following: anti-goat Cy3 (1:300; Jackson ImmunoResearch), anti-mouse and antirabbit Alexa Fluor-594 and Alexa Fluor-488 (1:500; Invitrogen). Biotinylated anti-rabbit and anti-mouse secondary antibodies (1:500; Vector Laboratories) were used along with ABC-Elite or VIP staining kits (Vector Laboratories). Cell count and statistical analyses were performed as described previously (Lu and Ramanan, 2011).

Western blotting. Total protein, $25 \mu \mathrm{g}$, prepared from neurospheres was immunoblotted by standard procedures. Primary antibodies were anti-SRF (1:5000; Santa Cruz Biotechnology) and anti-tubulin (1:10,000; SigmaAldrich). Secondary antibodies include anti-HRP (1:20,000; anti-mouse; Jackson ImmunoResearch; and anti-rabbit; Invitrogen). Chemiluminescence detection was performed using Immobilon reagent (Millipore).

Neurosphere culture. Neurosphere cultures and culture media were prepared as described previously (Dasgupta and Gutmann, 2005). Neonatal cortices were dissected and trypsinized at $37^{\circ} \mathrm{C}$ for $15 \mathrm{~min}$. Cells were mechanically dissociated by pipetting and incubated in $10 \%$ fetal calf serum medium for $10 \mathrm{~min}$ and pelleted by centrifugation. Dissociation medium was used to wash the cells before resuspending in growth medium containing $5 \mathrm{ng} / \mathrm{ml} \mathrm{FGF}$ and EGF. Samples were cultured at $250,000-500,000$ cells per $60 \mathrm{~mm}$ dish at $37^{\circ} \mathrm{C}$ with $5 \% \mathrm{CO}_{2}$ for $4 \mathrm{~d}$.

NPC proliferation analysis. $\mathrm{Srf}^{\mathrm{f} / \mathrm{f}}, \mathrm{Srf}^{\mathrm{f} /+} ; \mathrm{NesCre}$, and $\mathrm{Srf} / \mathrm{f} / \mathrm{f}$; $\mathrm{Cre}$ mice-derived neurospheres were dissociated by trypsin digestion and seeded at similar cell densities in 24-well plates with fresh growth medium. Every $12 \mathrm{~h}$, neurospheres from triplicate wells were collected and dissociated, and cell counts were determined. Cell growth was monitored over $84 \mathrm{~h}$, and results were plotted with sample mean and SEM. The experiment was repeated at least three times using NPCs generated from animals from different litters.

Secondary neurosphere analysis. NPCs from control and Srf-NestincKO brains were grown as neurospheres. After $4 \mathrm{DIV}$, neurospheres were dissociated and seeded as single cells. Approximately 50-70 single NPCs from each background were plated in 96-well plates and grown in fresh growth medium. The number of new neurospheres was monitored every $24 \mathrm{~h}$ and over $5 \mathrm{~d}$ to measure the percentage of cells that gave rise to a secondary neurosphere. The experiment was repeated twice using animals from different litters.

NPC differentiation. Neurospheres were trypsinized and washed with dissociation medium and were plated at 150,000 cells per well in 24-well plates in differentiation medium (growth medium without FGF and EGF). To enrich for astrocytes, the following pro-astrocytic growth factors and cytokines were supplemented either individually or collectively: CNTF, 100 ng/ml (Peprotech); LIF, 40 ng/ml (Millipore); CT-1, 50 ng/ml (Peprotech); BMP-2, $30 \mathrm{ng} / \mathrm{ml}$ (Peprotech); interleukin-6 (IL6), 20 $\mathrm{ng} / \mathrm{ml}$ (Peprotech); sIL6R, $25 \mathrm{ng} / \mathrm{ml}$ (Peprotech); and Jagged-1 (Jag-1), $500 \mathrm{ng} / \mathrm{ml}$ (R \& D Systems). Cells were fixed using $4 \%$ sucrose in $4 \%$ paraformaldehyde in PBS and immunostained $4 \mathrm{~d}$ after induction. To enrich for oligodendrocytes, PDGF at $10 \mathrm{ng} / \mathrm{ml}$ (Peprotech) and 3,3',5triiodo-L-thyronine (T3) at $30 \mathrm{ng} / \mathrm{ml}$ (MP Biomedicals) were added to NPCs. The percentage of oligodendrocyte precursor cells (OPCs) generated was analyzed at $2 \mathrm{~d}$ after induction, and the percentage of differentiated oligodendrocytes was analyzed at $4 \mathrm{~d}$ after induction.

Generation of murine stem cell virus. The retroviral murine stem cell virus vector (MSCV) was obtained as a gift from Dr. David Gutmann (Washington University School of Medicine) (Dasgupta and Gutmann, 2005). SRF and a constitutively active variant of SRF (SRF-VP16) were cloned into the MSCV plasmid. For generating virulent particles, HEK293T cells were transfected with each of the MSCV constructs along with complementary T-helper plasmid using Fugene HD (Roche). Culture supernatant containing the virus particles was collected at 48 and $72 \mathrm{~h}$ and filtered through a $0.4 \mu \mathrm{m}$ syringe filter. For viral transduction, NPCs were trypsinized and grown in a mixture of $20 \%$ fresh NPC growth medium and $80 \%$ viral supernatant for $2 \mathrm{~d}$ before switching to $100 \%$ NPC growth medium for an additional 3-4 d. The empty MSCV was used as a control for analyzing the effects of MSCV-SRF and MSCVSRF-VP16 in rescue experiments.

\section{Results}

\section{SRF ablation results in reduced astrocyte numbers in vivo}

SRF has been shown to regulate cell-fate specification in a cellautonomous manner in several organ systems in mice (Miano et al., 2004; Parlakian et al., 2004; Sandbo et al., 2009; Verdoni et al., 2010), but whether SRF has similar roles in the nervous system has remained unexplored. To address this, we conditionally deleted SRF within NPCs using a Nestin-Cre transgenic mouse line (Srf-NestincKO) (Lu and Ramanan, 2011). The Srf-Nestin-cKO mice died neonatally and did not exhibit any defects in cell survival, neurogenesis, or neuronal subtype specification (Lu and Ramanan, 2011). Because neurogenesis was unaffected in Srf-Nestin-cKO mice, we examined astrocytes at $\mathrm{P} 0.5$ by immunostaining for the astrocyte marker GFAP. We found that Srf-Nestin-cKO mice exhibited nearly $60 \%$ reduction in astrocytes in multiple brain regions, including neocortex, hippocampus, corpus callosum, and thalamus (Fig. $1 A$ and data not shown). We next assessed SRF deletion in astrocytes. Coimmunostaining for GFAP and SRF revealed that SRF is robustly expressed in astrocytes of control mice but not in Srf-Nestin-cKO mice (Fig. $1 B$ ). We also confirmed that reduced astrocytes in Srf-Nestin-cKO mice were not attributable to diminished GFAP expression. Immunostaining brain sections from Srf-Nestin-cKO and control mice using two other astrocyte markers, Aldh1L1 (Cahoy et al., 2008) and $\mathrm{S} 100 \beta$, showed that control mice had significantly more astrocytes in several brain regions, including neocortex and hippocampus, compared with Srf-Nestin-cKO mice (Fig. $1 C-F ; n=5$ mice).

Our recent findings revealed that $S r f-\mathrm{Nestin}-\mathrm{cKO}$ mice did not exhibit any deficits in neurogenesis or increased apoptosis during development (Lu and Ramanan, 2011). However, there 
A

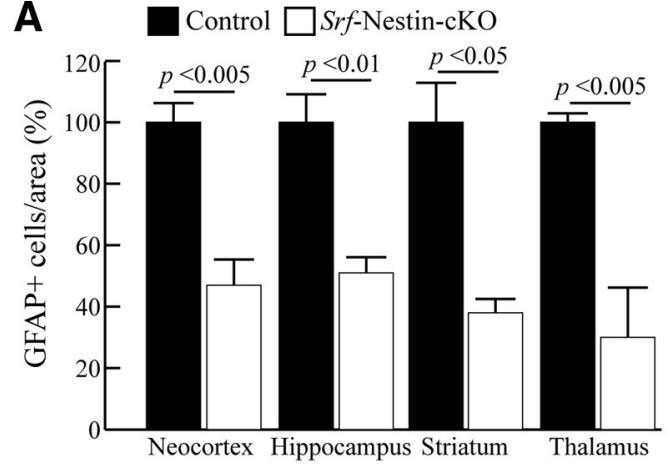

C Neocortex Striatum

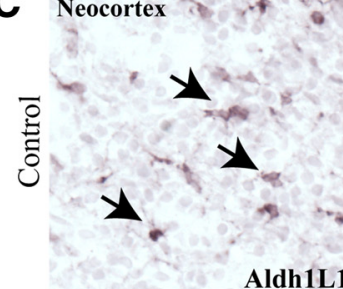

Aldh1L1
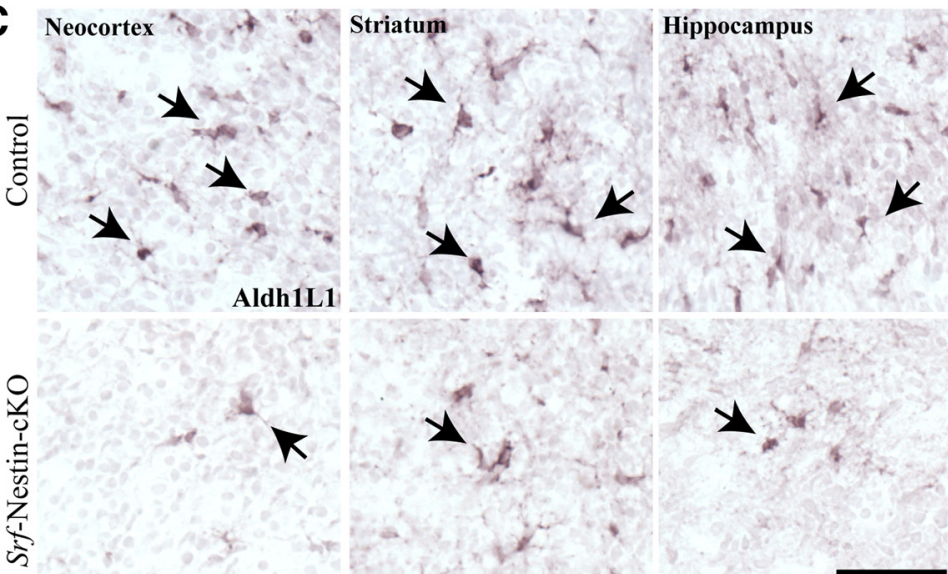

D Control
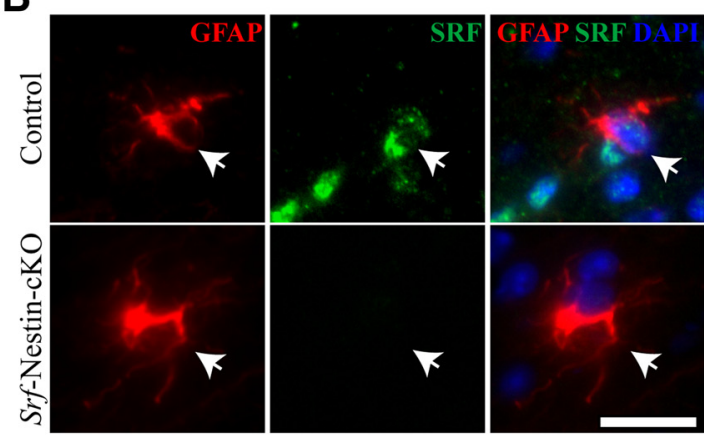

$\square$ Srf-Nestin-cKO

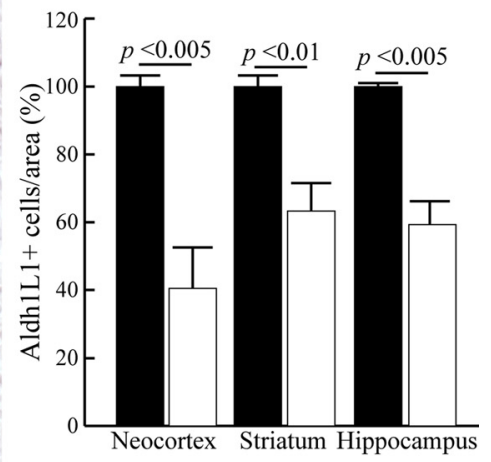

\section{E}

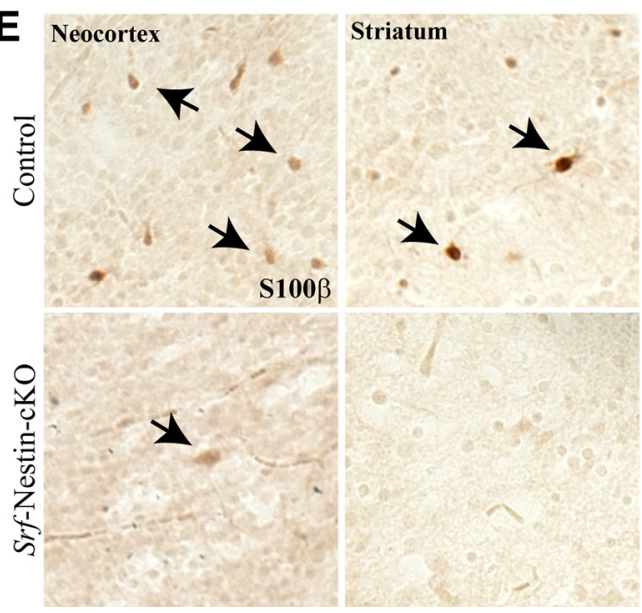

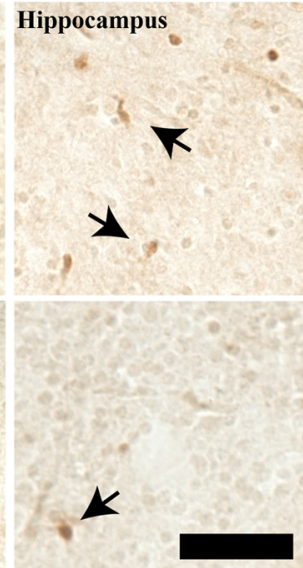

\section{F $\square$ Control $\square$ Srf-Nestin-cKO}

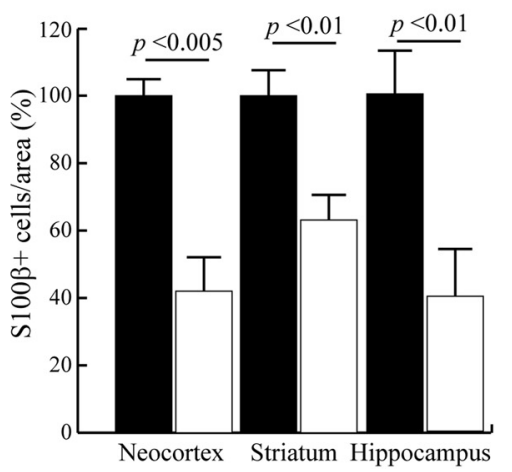

Figure 1. SRF is required for astrocyte specification in vivo. A, Astrocytes were immunostained using anti-GFAP antibodies. Cell count analyses from several brain regions, including neocortex, hippocampus, striatum, and thalamus, indicate a significant reduction in astrocytes in Srf-Nestin-cKO mice compared with control littermates ( $n=5$ mice). $\boldsymbol{B}$, Coimmunofluorescence staining for SRF and GFAP shows robust SRF staining in astrocytes in control mice but not in Srf-Nestin- CKO mice ( $n=4$ mice). Scale bar, $10 \mu \mathrm{m}$ (shown here is hippocampus). $C$, Aldh1L1 immunostaining of P0.5 brain sections from control and Srf-Nestin- CKO mice shows astrocytes in several brain regions. Scale bar, $50 \mu \mathrm{m}$. D, Quantification of cell counts from $\boldsymbol{C}(n=5$ mice). $\boldsymbol{E}$, Immunostaining for $S 100 \beta^{+}$astrocytes in control and Srf-Nestin-cKO mutant mice. Scale bar, $50 \mu \mathrm{m}$. $\boldsymbol{F}$, Quantification of cell counts in $\boldsymbol{D}$ ( $n=5$ mice).

was an increase in proliferative precursor cells in the subventricular zone in Srf-Nestin-cKO mice (Lu and Ramanan, 2011), which is possibly a result of impairment in glial lineage commitment. Together, these findings suggest that the decrease in astrocytes in neonatal Srf-Nestin-cKO mice reflects a critical requirement of SRF for astrocyte differentiation in vivo.

\section{SRF deficiency in NPCs impairs astrocyte specification in vitro}

To study the role of SRF in astrocyte specification further, we used the neurosphere culture system (Dasgupta and Gutmann,
2005). NPCs cultured from P0.5 cortices of control and SrfNestin-cKO brains formed neurospheres within 2-3 d in the presence of EGF and FGF as mitogens and were physically indistinguishable from one another (Figs. $2 A, 3 A$ and data not shown). Coimmunostaining for the NPC marker Nestin and SRF showed that neurospheres from control mice exhibited strong immunoreactivity for both SRF and Nestin. In contrast, neurospheres from Srf-Nestin-cKO mice were positive for Nestin but lacked SRF (Fig. 2A). Immunoblotting of total protein isolated from control and SRF-deficient neurospheres further confirmed $\mathrm{SRF}$ deletion in NPCs from Srf-Nestin-cKO mice (Fig. 2B). 

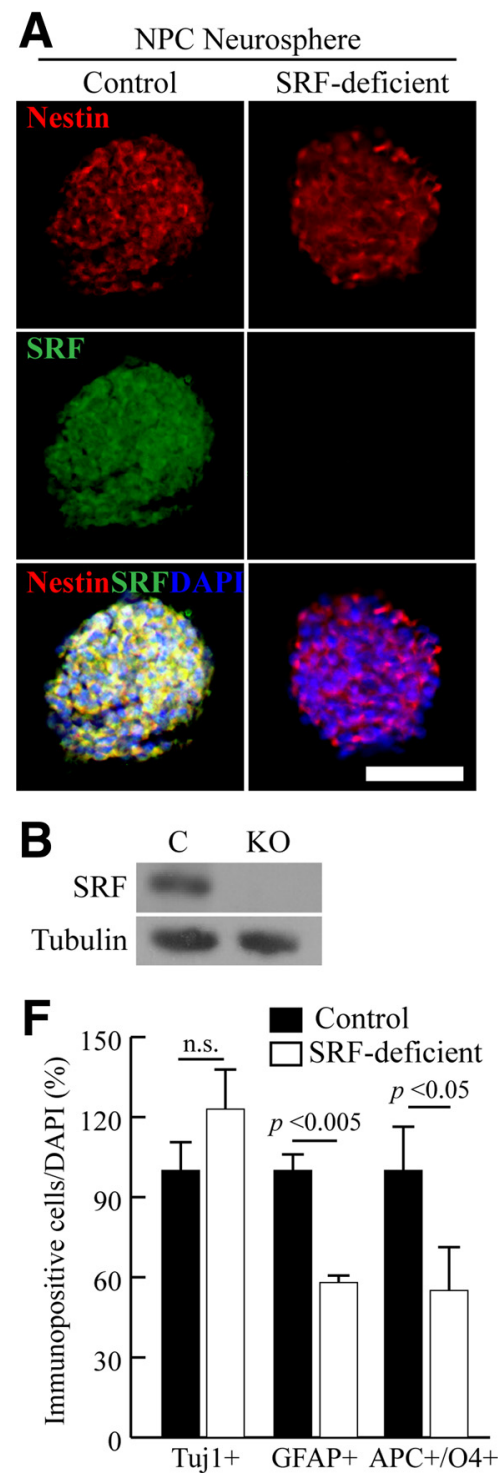
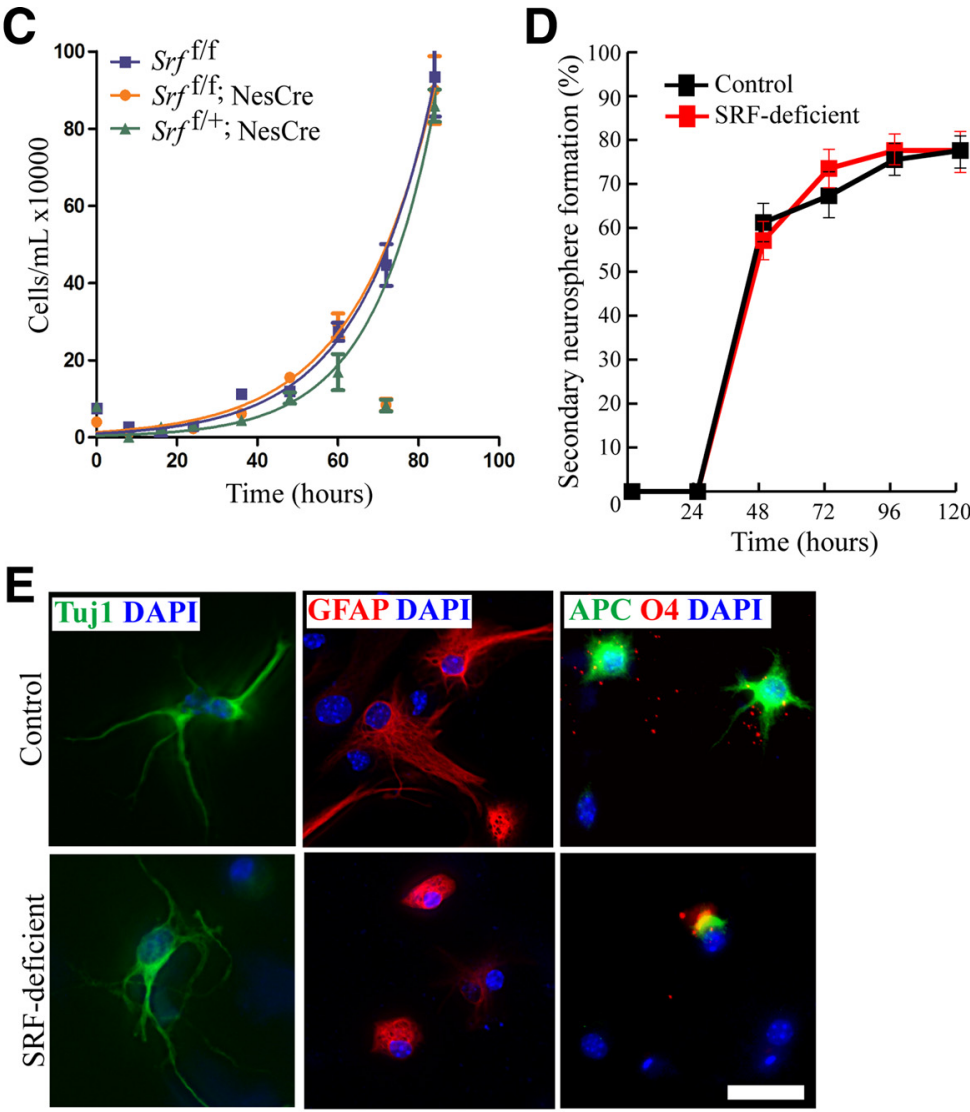

Figure 2. SRF-deficient NPCs exhibit normal proliferation and self-renewal. $\boldsymbol{A}$, NPCS, identified by Nestin expression, were isolated from forebrains of P0.5 control and Srf-Nestin- cK0 mice and cultured as neurospheres for 4 DIV (top row). Only neurospheres from control mice, but not Srf-Nestin-cKO mice, robustly express SRF (middle row). Bottom row shows merged image of top and middle rows along with DAPI. Scale bar, $50 \mu \mathrm{m}$. B, Immunoblotting of total protein from cultured NPCs shows SRF loss in neurospheres from Srf-Nestin-cKO mice. C, Control. C, NPCs from P0.5 control, Srf-Nestin heterozygous, and Srf-Nestin-cKO mice were grown as neurospheres, which were collected at the indicated times, and cell count was determined. SRF-deficient NPCs exhibit comparable growth rates with that of control and SRF heterozygous cells $(n=3)$. D, NPCs growing as neurospheres were trypsinized, and the number of neurospheres generated from single cells was determined at the indicated time points. The ability of single SRF-deficient NPCs to form secondary neurospheres was comparable with that of control NPCs ( $n=2$ ). $\boldsymbol{E}$, NPCs from control and Srf-Nestin-cKO mice could generate neurons (Tuj ${ }^{+}$), astrocytes (GFAP ${ }^{+}$), and differentiated oligodendrocytes ( $\mathrm{APC}^{+} / 04^{+}$) during mitogen withdrawal. Astrocytes and oligodendrocytes derived from SRF-deficient NPCs appeared less elaborate than those from control NPCs. Scale bar, $10 \mu \mathrm{m}$. $\boldsymbol{F}$, Cell count analyses from $\boldsymbol{E}$ show a significant decrease in astrocytes and oligodendrocytes, but not neurons, generated from SRF-deficient NPCs $4 \mathrm{~d}$ after induction.

Likewise, SRF was completely ablated in NPCs isolated from cortices of E12.5 Srf-Nestin-cKO mice (data not shown). We next analyzed the effect of SRF deletion on NPC proliferation and found that SRF-deficient and SRF-heterozygous NPCs had rates of proliferation comparable with NPCs from control mice (Fig. $2 C$ ). We analyzed the capacity of SRF-deficient NPCs to selfrenew by assessing their ability to form clonal secondary neurospheres from single NPCs. SRF loss did not affect the capacity of NPCs to form secondary neurospheres (Fig. 2D). These findings demonstrate that SRF deletion in NPCs does not affect NPC growth rate and capacity for self-renewal in vitro.

NPCs are multipotent and are capable of differentiating into neurons, astrocytes, and oligodendrocytes following mitogen withdrawal (Rao, 1999; Liu and Rao, 2004; Ahmed, 2009). We found that SRF-deficient NPCs were capable of generating neurons, astrocytes, and oligodendrocytes as identified by the expression $\beta$-tubulin III (TujI) in neurons, GFAP in astrocytes, and coexpression of APC and $\mathrm{O} 4$ in differentiated oligodendrocytes (Hegedus et al., 2007; Fancy et al., 2011) (Fig. 2 E). Similar to that observed in vivo, SRF-deficient NPCs generated significantly fewer astrocytes and oligodendrocytes compared with wild-type NPCs, whereas similar number of neurons was generated (Fig. $2 F)$. These results confirm that SRF is dispensable for neurogenesis but is critical for glial specification.

\section{SRF-deficient NPCs fail to respond to pro-astrocytic stimuli} Astrocyte cell fate can be induced by several different extracellular ligands. We tested the ability of SRF-deficient NPCs to generate 
A
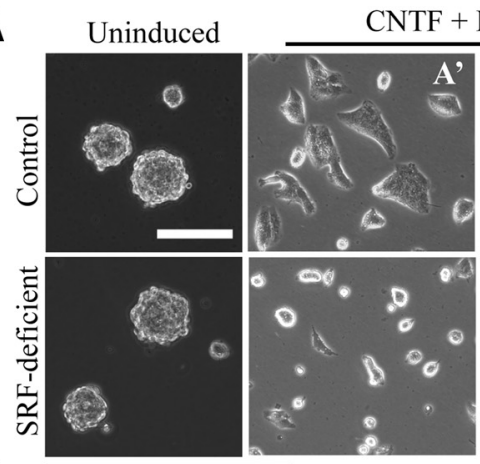

B
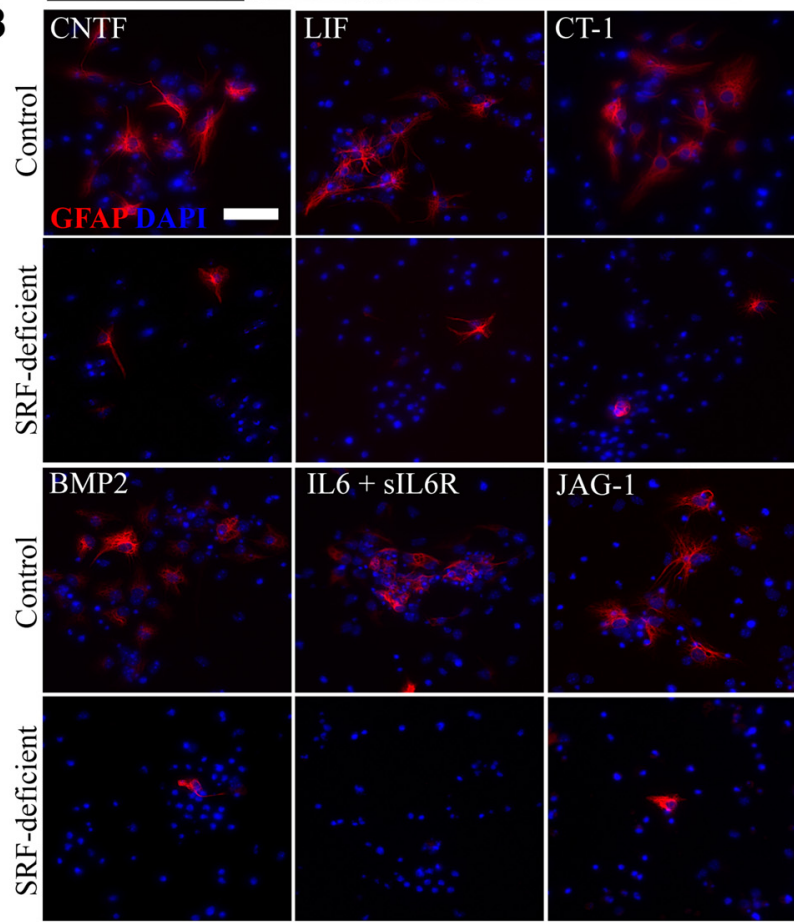

C

Control NPC

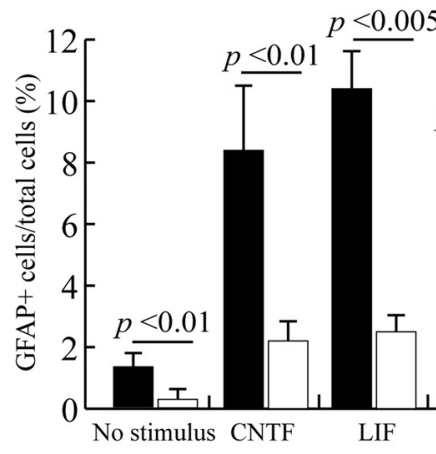

SRF-deficient NPC

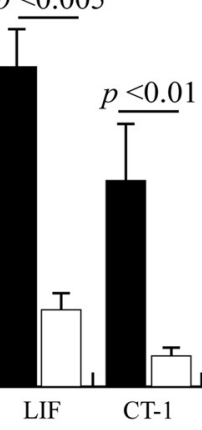

$p<0.0$

CT-1
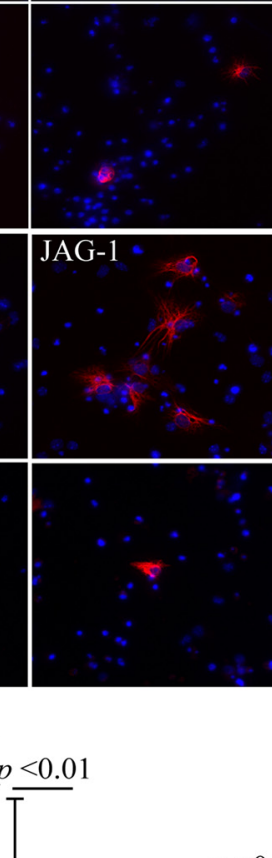
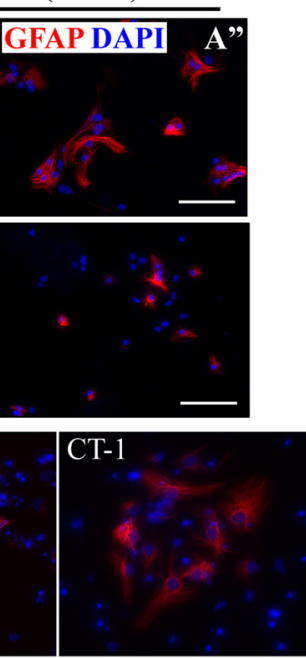

D

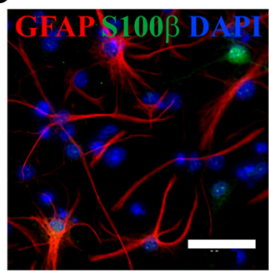

SRF-deficient
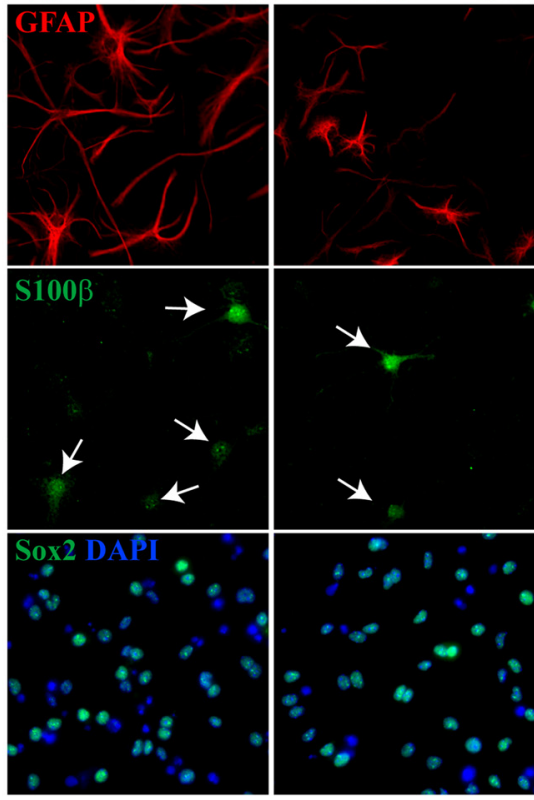

E

Control NPC $\square$ SRF-deficient NPC

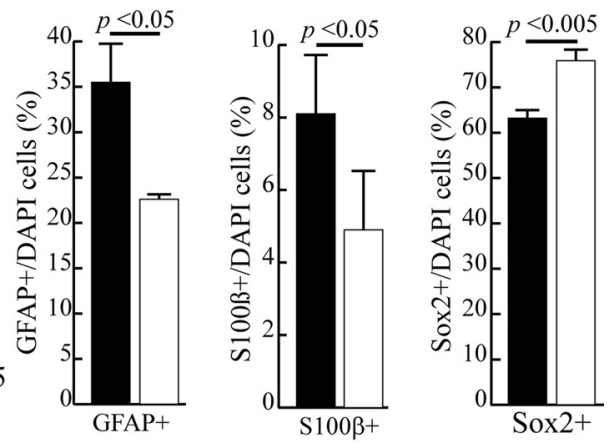

Figure 3. SRF-deficient NPCS fail to differentiate in response to pro-astrocyte stimuli. A, NPCs from control and Srf-Nestin- CKO mice were cultured as neurospheres for 4 DIV. The neurospheres were trypsinized and induced with CNTF (100 ng/ml) and LIF (40 ng/ml) $\left(A^{\prime}, A^{\prime \prime}\right)$. SRF-deficient NPCs generated fewer astrocytes compared with wild-type cells as visualized by GFAP immunostaining $\left(A^{\prime \prime}\right)$. The SRF-deficient astrocytes also appeared smaller and less stellar $\left(\boldsymbol{A}^{\prime}\right)$. $\boldsymbol{A}^{\prime}$ and $\boldsymbol{A}^{\prime \prime}$ represent independent experiments. $\boldsymbol{B}$, NPCs from control and Srf-Nestin-cKO mice were induced into astrocytes by several pro-astrocytic ligands as indicated. At $4 \mathrm{~d}$ after induction, SRF-deficient NPCs generated significantly fewer astrocytes compared with NPCs from control littermates as visualized by GFAP immunolabeling. Scale bar, $25 \mu \mathrm{m}$. C, Quantification of GFAP ${ }^{+}$astrocytes in $\boldsymbol{B}$ shows that SRF is critically required under all these induction conditions for astrocyte specification ( $n=3$ experiments). $\boldsymbol{D}$, Control and SRF-deficient NPCs were cultured in the presence of all ligands shown in $\boldsymbol{B}$, and cells were immunostained at 4 DIV for astrocytes (GFAP and S100 $\beta$ ) and NPCs (Sox2). Arrows point to S100 $\beta^{+}$cells. Scale bar, $25 \mu$ m. $\boldsymbol{E}$, Cell count analyses for $\boldsymbol{D}$ show that loss of SRF impairs commitment to astrocytes even in the presence of several pro-astrocyte signals and that more SRF-deficient NPCs remain as Sox ${ }^{+}{ }^{-}$precursors in culture.

astrocytes in the presence of these known pro-astrocytic ligands. After mitogen withdrawal and in the presence of CNTF and LIF, wild-type NPCs differentiated predominantly into astrocytes at 4 DIV with characteristic stellar morphology along with $<0.5 \%$ neurons and oligodendrocytes (Fig. $3 A, A^{\prime}, A^{\prime \prime}$ and data not shown). In contrast, SRF-deficient NPCs generated significantly fewer astrocytes compared with wild-type NPCs, and a large proportion of cells remained spherical and precursor cell like (Fig. 
A
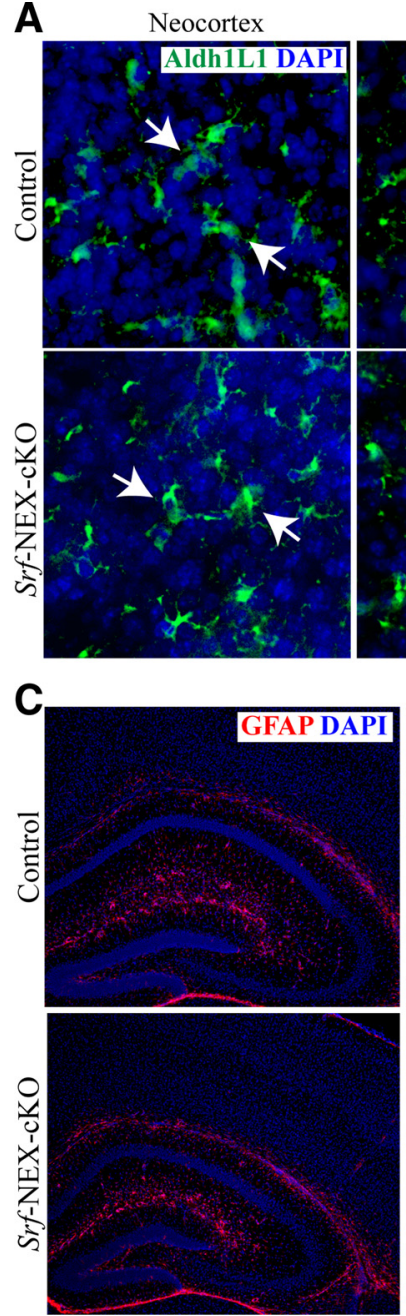

Hippocampus
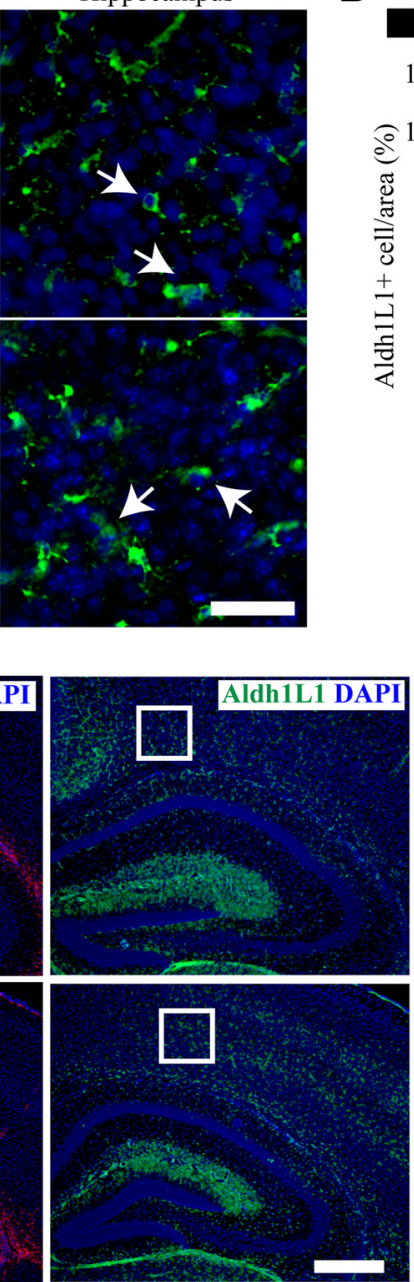

B
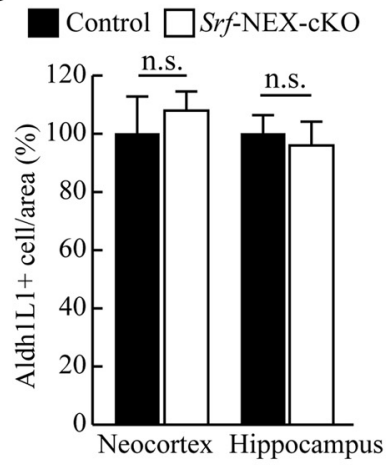

D

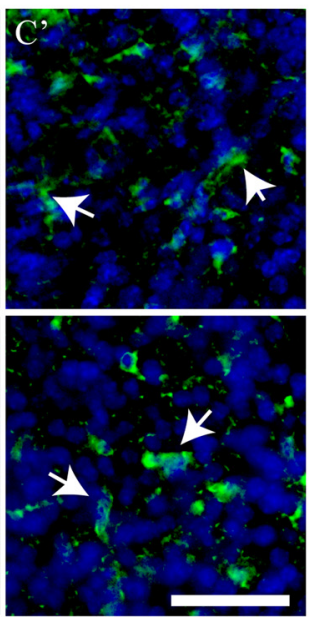

Control $\square$ Srf-NEX-cKO

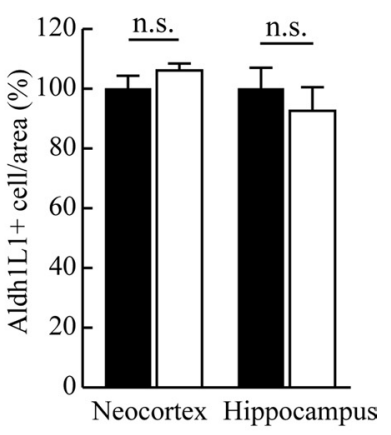

Figure 4. SRF deletion in neurons does not affect astrocyte differentiation. $A$, Brain sections from P0.5 control and Srf-NEX-cK0 mice were immunostained using anti-Aldh $1 \mathrm{~L} 1$ antibody to label all astrocytes (arrows). Neocortex and hippocampus are shown. Scale bar, $20 \mu \mathrm{m}$. B, Quantification of astrocyte cell count from $A$ shows no significant difference in astrocytes in Srf-NEX-cKO mice compared with control littermates $\left(n=3\right.$ mice). C, Immunofluorescence staining for GFAP and Aldh1L1 to label astrocytes in 3-month-old control and Srf-NEX-cKO mice. No GFAP ${ }^{+}$astrocytes were seen in neocortex because GFAP expression in adult brain is restricted to astrocytes in the white matter and hippocampus but not in the neocortex. In contrast, Aldh1L1 labels all astrocytes, including those in neocortex of both groups of mice. Scale bar, $200 \mu \mathrm{m}$. $\mathbf{C}^{\prime}$ represents magnified view of the boxed region. Scale bar, $20 \mu \mathrm{m} . \mathbf{D}$, Quantification of Aldh1L1 ${ }^{+}$astrocytes in $\mathbf{C}$ shows no significant difference in neocortex and hippocampus of Srf-NEX-cKO mice and control littermates ( $n=3$ mice).

$\left.3 A^{\prime}, A^{\prime \prime}\right)$. Furthermore, the small population of SRF-deficient cells that were GFAP positive $\left(\mathrm{GFAP}^{+}\right)$did not develop elaborate astrocytic processes and stellate morphology that were exhibited by wild-type astrocytes.

We also tested the ability of other cytokines and pro-astrocytic ligands, including CT-1, IL6, BMP-2, and Jag-1 to promote astrocyte fate choice (Kahn and De Vellis, 1994; März et al., 1999; Nakashima et al., 2001; Ochiai et al., 2001; Takizawa et al., 2001; Yanagisawa et al., 2001; Grandbarbe et al., 2003; Barnabé-Heider et al., 2005; Namihira et al., 2009). When cultured in the presence of each of the above ligands, SRF-deficient NPCs generated significantly fewer astrocytes compared with control NPCs (Fig. $3 B, C$ ), suggesting that SRF might be broadly required for astrocyte specification rather than being necessary for mediating a particular pro-astrocyte signaling transduction pathway. We next asked whether these stimuli added together were capable of overcoming the impairment in astrocyte differentiation exhibited by SRF-deficient NPCs. Immunostaining for anti-GFAP and anti-S100 $\beta$ at 4-days after induction showed attenuated astrocyte specification exhibited by SRF-deficient NPCs even in the presence of multiple pro-astrocytic stimuli (Fig. $3 D, E$ ).
Because SRF deletion in NPCs does not lead to an increase or impairment in neurogenesis but rather a decrease in astrocytes and oligodendrocytes, we sought to determine the fate of NPCs remaining in culture. Immunostaining for Sox2, a transcription factor expressed specifically by NPCs, showed that, compared with $63 \%$ of control cells, $76 \%$ of SRF-deficient cells were Sox ${ }^{+}$at $4 \mathrm{~d}$ after induction (Fig. $3 D, E$ ). This suggests that, in the absence of SRF, NPCs are less able to respond to pro-astrocytic signals and consequently, more of them remain as precursors. Furthermore, we did not observe any significant increases in the number of precursor cells in these cultures after astrocyte induction (data not shown), which suggests that the NPCs are not actively proliferating in the absence of mitogens (EGF and FGF). Therefore, the decrease in the percentage of $\mathrm{GFAP}^{+}$cells is not attributable to an increase in the pool of proliferating SRF-deficient precursor cells. This increase in Sox ${ }^{+}$cells in SRF-deficient cultures was similar to that observed in the brains of P0.5 Srf-Nestin-cKO mice, which exhibited an increase in p-histone- $\mathrm{H} 3^{+}, \mathrm{Ki}^{+} 7^{+}$, and Sox $2^{+}$cells along the subventricular zone and in neocortex (Lu and Ramanan, 2011). 

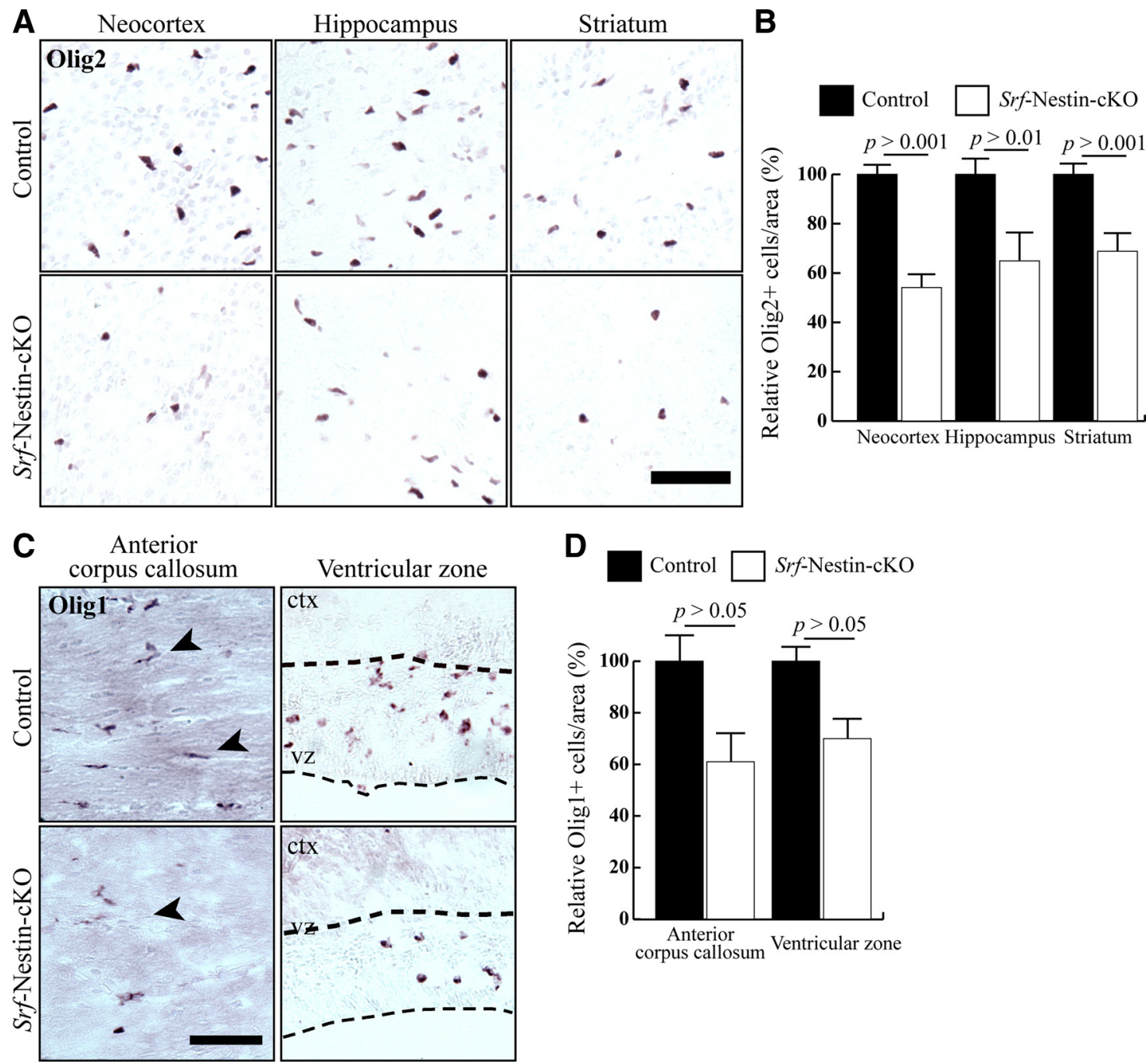

Figure 5. SRF is critical for oligodendrocyte specification in vivo. $A, O P(s$ in the brain were identified by immunostaining for Olig2 expression in Srf-Nestin- CKO and control mice at P0.5. Shown here are neocortex, hippocampus, and striatum ( $n=3$ mice). Scale bar, $50 \mu \mathrm{m}$. $\boldsymbol{B}$, Quantification of Olig2 ${ }^{+}$cells per area (in square micrometers) in $\boldsymbol{A}$ shows that the number of 0 lig $2^{+}$OPCs is reduced in Srf-Nestin- CKO mutants. C, Olig ${ }^{+}$OPCs were also analyzed at P0.5 in control and Srf-Nestin- cKO brains. Shown here is the anterior corpus callosum and ventricular zone (vz). ctx, Neocortex ( $n=3$ mice). Scale bar, $50 \mu \mathrm{m}$. D, Quantification of 0 lig $1^{+}$cells per area (square micrometers) in Calso shows a significant reduction of OPC population in the mutant brain.

\section{SRF is required cell autonomously for astrocyte} differentiation in vivo

Recent observations have shown that newborn neurons and committed NPCs promote astrocyte specification by secreting Notch ligands, such as Jag-1, and thus activating Notch signaling in neighboring uncommitted NPCs (Namihira et al., 2009). Because SRF is also deleted in neurons in Srf-Nestin-cKO mice, the deficits in astrocytes could be attributable to non-cellautonomous effect from SRF-deficient neurons. To address whether SRF-deficient neurons contribute to the deficits in astrocytes observed in Srf-Nestin-cKO mice, we analyzed astrocytes in Srf-NEXcKO mice, in which SRF deletion was restricted to glutamatergic neurons of the neocortex and hippocampus starting at approximately E11.5 (Lu and Ramanan, 2011). Immunostaining of P0.5 brains from Srf-NEX-cKO mice and control littermates using antiGFAP and anti-Aldh1L1 antibodies showed no differences in the number of astrocytes localized in neocortex and hippocampus of Srf-NEX-cKO mice compared with control littermates (Fig. $4 A, B$ and data not shown). Unlike the Srf-Nestin-cKO mutant mice, the Srf-NEX-cKO mice do not exhibit neonatal lethality. Analyzing the brains of 3-month-old Srf-NEX-cKO mice, we observed no deficits in astrocytic numbers compared with control littermates (Fig. $\left.4 C, C^{\prime}\right)$. Together, these observations indicate that SRF plays a cellautonomous role within NPCs to promote astrocyte specification both in vitro and in vivo and that SRF deletion in neurons does not have any discernible effect on astrocyte specification and maintenance.

\section{Srf-Nestin-cKO mutant mice also exhibit a reduction in oligodendrocyte precursors}

SRF-deficient NPCs generated fewer astrocytes and oligodendrocytes during mitogen withdrawal in culture (Fig. $2 E, F$ ). We asked whether this also reflected a role for SRF in oligodendrocyte specification in vivo. Oligodendrocytes are mostly generated in the first few weeks after birth (Sauvageot and Stiles, 2002). However, OPCs can be seen in the brain as early as E10.5-E14.5 (Woodruff et al., 2001). Immunostaining for OPCs using Olig1 and Olig2 antibodies (Lu et al., 2000; Zhou et al., 2000) revealed significantly $(40-50 \%)$ fewer OPCs in multiple regions of SrfNestin-cKO brains compared with wild-type control littermates (Fig. 5A-D). These findings suggest that SRF is also critical for oligodendrocyte specification in vivo. 
A $\quad$ T3 + PDGF (2 DIV)

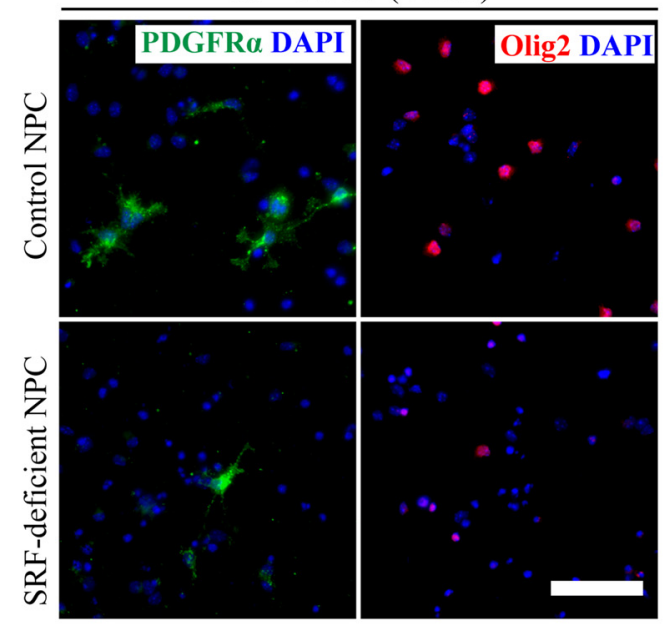

Control NPC $\square$ SRF-deficient NPC

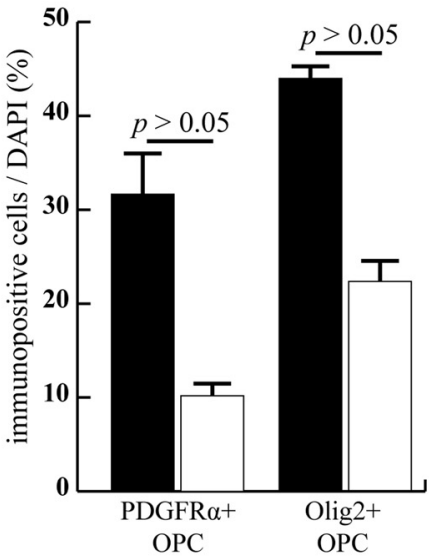

C

T3 + PDGF (4 DIV)
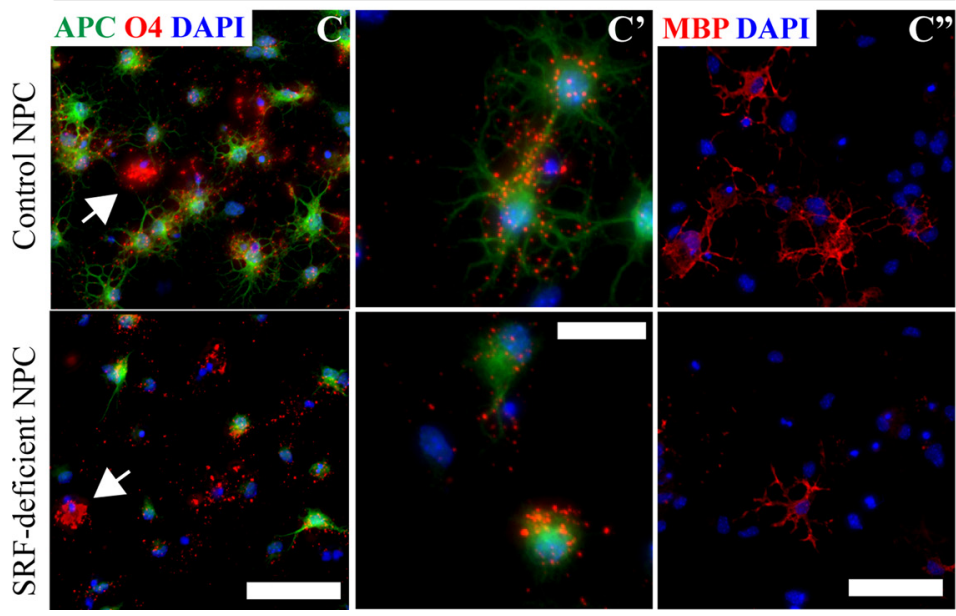

D

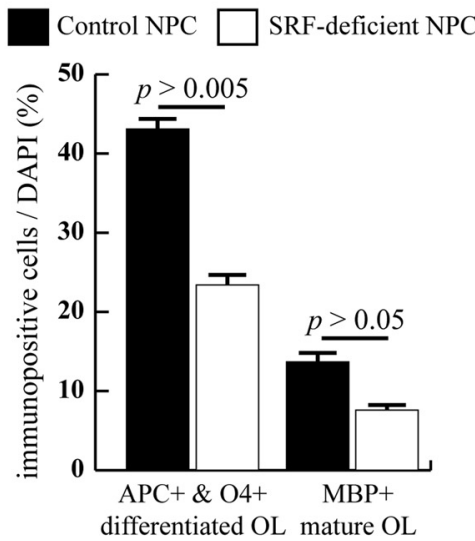

Figure 6. SRF-deficient NPCs show impairment in oligodendrocyte specification. $A$, Control and SRF-deficient NPCs were induced for oligodendrocyte lineage commitment using T3 (10 ng/ml) and PDGF $(2.5 \mathrm{ng} / \mathrm{ml})$. At 2 DIV, OPCs were identified by Olig2 ${ }^{+}$or PDGFR $\alpha^{+}$immunoreactivity. Scale bar, $25 \mu \mathrm{m}$. B, Quantification of PDGFR $\alpha^{+}$or 0 lig $2^{+}$cells show that SRF-deficient NPCs exhibit a reduced capacity for generating OPCS. C, At 4 DIV, differentiated oligodendrocytes were identified from APC and 04 coexpression. Magnified images of colocalization of APC and 04 staining are shown in $\boldsymbol{C}^{\prime}$. Arrows point to late OPCs expressing 04 alone. Myelinating mature oligodendrocytes identified by MBP expression were also reduced in SRF-deficient cultures ( $\boldsymbol{C}^{\prime \prime}$ ). Scale bars: $\boldsymbol{C}$, $\boldsymbol{C}^{\prime \prime}$, $25 \mu \mathrm{m} ; \boldsymbol{C}^{\prime}, 10 \mu \mathrm{m}$. D, Cell count analysis demonstrates that, at 4 DIV, the number of differentiated oligodendrocytes is also significantly reduced in SRF-deficient NPC cultures.

\section{SRF-deficient NPCs show impairment in oligodendrocyte specification}

Astrocytes have been shown to promote OPC survival in vitro by the secretion of PDGF (Gard et al., 1995). Therefore, the reduced OPCs observed in Srf-Nestin-cKO mutant brains could be attributable to reduced astrocytes or this could reflect a cellautonomous role for SRF in oligodendrocyte specification. PDGF, which promotes OPC proliferation (McKinnon et al., 1990; Robinson and Miller, 1996), and T3, which drives oligodendrocyte differentiation (Almazan et al., 1985), were supplemented to induce and enrich for differentiated oligodendrocytes. We found that SRF-deficient NPCs generated twofold to threefold less PDGFR $\alpha^{+}$and Olig $2^{+}$OPCs at $2 \mathrm{~d}$ after induction and similar deficits in $\mathrm{APC}^{+} / \mathrm{O}_{4}{ }^{+}$and $\mathrm{MBP}^{+}$differentiated oligodendrocytes at $4 \mathrm{~d}$ after induction compared with wild-type NPCs (Fig. $6 A-D$ ). We observed $<0.5 \%$ of neurons and astrocytes under these pro-oligodendrocyte induction conditions (data not shown). These findings recapitulate the in vivo observations made in Srf-Nestin-cKO brains and suggest that SRF plays a cell-autonomous role in oligodendrocyte specification and maturation.
Ectopic expression of SRF rescues both astrocyte and oligodendrocyte specification in SRF-deficient NPCs

We asked whether the defects in astrocyte and oligodendrocyte specification observed in SRF-deficient NPCs reflects a fundamental defect in differentiation in the absence of SRF or whether these deficits suggest a requirement for SRFdependent transcription for glial cell-fate specification. NPCs from Srf-Nestin-cKO and control littermates were transduced with MSCV expressing either wild-type SRF (MSCV$\mathrm{SRF}$ ) or empty vector (MSCV) alone. In control experiments using the MSCV-SRF virus, we found nearly $98 \%$ transduction efficiency of SRF-deficient NPCs at $4 \mathrm{~d}$ after infection using immunostaining for SRF (data not shown). We also found that MSCV infection did not affect proliferation rates of control and SRF-deficient NPCs (data not shown). Ectopic expression of SRF alone in wild-type NPCs did not potentiate glial differentiation (Fig. $7 A-D$ ). However, reintroduction of SRF into SRF-deficient NPCs was sufficient to rescue the deficits in both astrocyte and oligodendrocyte differentiation in the presence of CNTF/LIF and PDGF/T3, respectively, to the levels seen in wild-type NPCs (Fig. 7A-D). 
SRF is not sufficient to promote glial differentiation but augments the effects of astrocyte induction

Our findings thus far suggest that SRF is required cell intrinsically to regulate glial specification. We next asked whether activation of SRF-dependent transcription alone is sufficient to promote glial specification. For this, we expressed constitutively active SRF, SRF-VP16, a chimeric protein generated by fusing the DNA binding domain of SRF with the strong transactivation domain of VP16 protein from herpes simplex virus (Johansen and Prywes, 1994; Schratt et al., 2002). SRFVP16 binds to target SRF binding elements (termed the CArG box sequence) in the regulatory regions of its target genes and activates gene expression even in the absence of any stimuli that stimulate SRFdependent transcription. SRF-deficient and control NPCs were transduced with MSCV expressing either SRF-VP16 or empty vector and were allowed to differentiate after mitogen withdrawal. At $4 \mathrm{~d}$ after mitogen withdrawal, we observed that SRF-VP16 expression alone was not sufficient to generate more astrocytes compared with empty vector and even exhibited an inhibitory effect on astrocyte specification (Fig. $8 A, B$ ). However, when NPCs were induced for astrocyte differentiation by the addition of CNTF and LIF, we found that SRF-VP16 significantly potentiated astrocyte differentiation to a similar extent in both control and SRFdeficient NPCs (Fig. 8A,B).

Similarly, we also found that SRFVP16 was not sufficient to induce oligodendrocyte differentiation in the absence of mitogens (Fig. 8C,D). Interestingly, in contrast to that observed for astrocytes, expression of SRF-VP16 in NPCs inhibited oligodendrocyte differentiation in the presence of pro-oligodendrocyte factors T3 and PDGF (Fig. 8C,D). A recent study showed that SRF-VP16 expression in neurons inhibited oligodendrocyte maturation through a paracrine mechanism involving connective tissue growth factor (CTGF) (Stritt et al., 2009). Our results suggest that SRF-VP16 expression might exert a similar but an autocrine inhibitory effect on NPCs to regulate oligodendrocyte differentiation. In summary, our results identified SRF as a novel transcriptional regulator critical but not sufficient for astrocyte and oligodendrocyte differentiation in the brain.

\section{Discussion}

Astrocytes are the most abundant cell type in the mammalian brain and perform critical roles in nearly every facet of brain function, including synaptogenesis, neurotransmitter homeostasis, and synaptic plasticity. Oligodendrocytes are responsible for the generation and maintenance of myelination that facilitates neuronal salutatory transmission as well as for providing trophic support for the survival of neurons and growth of axons. In this
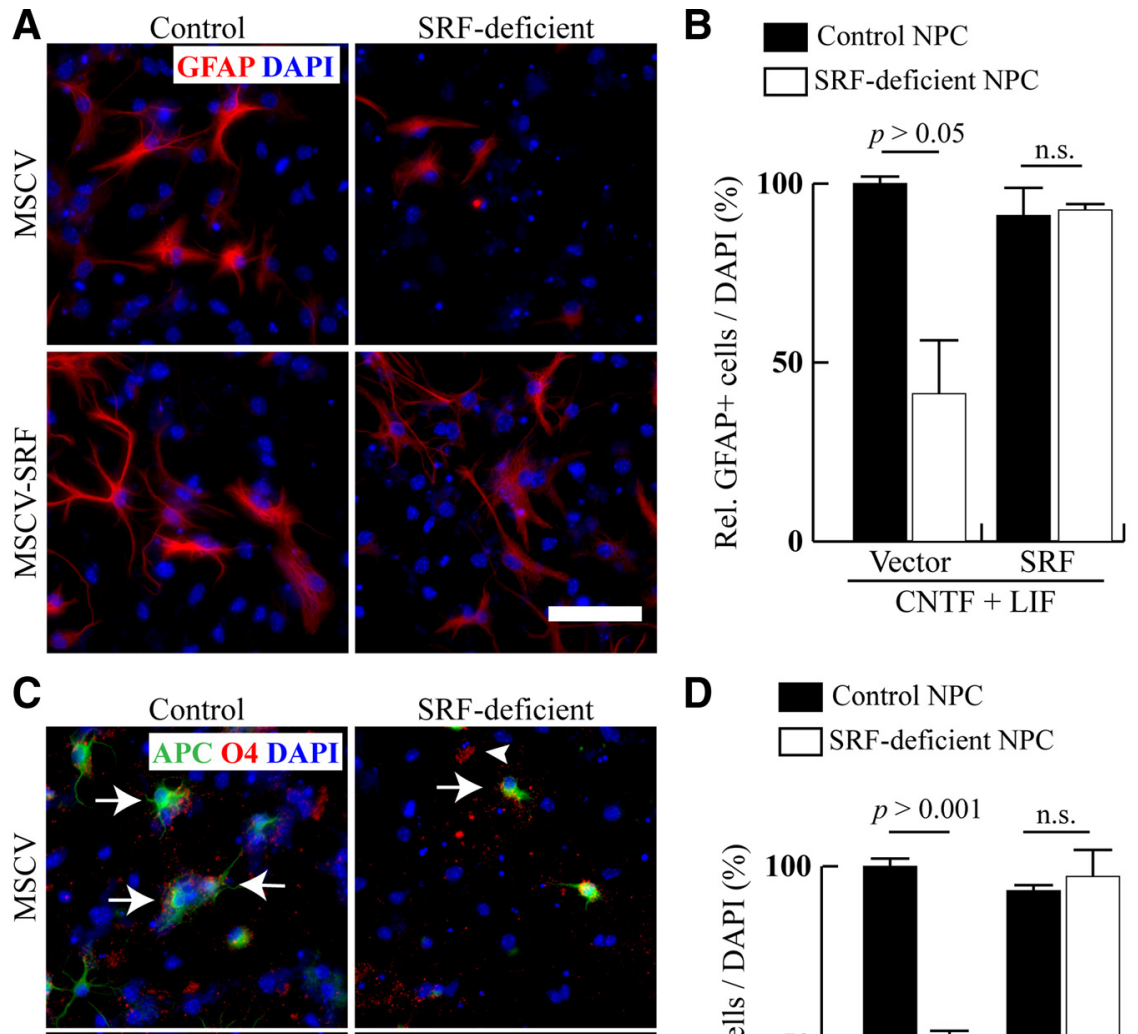

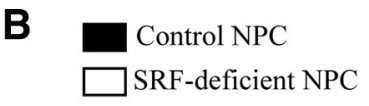 \\ B}
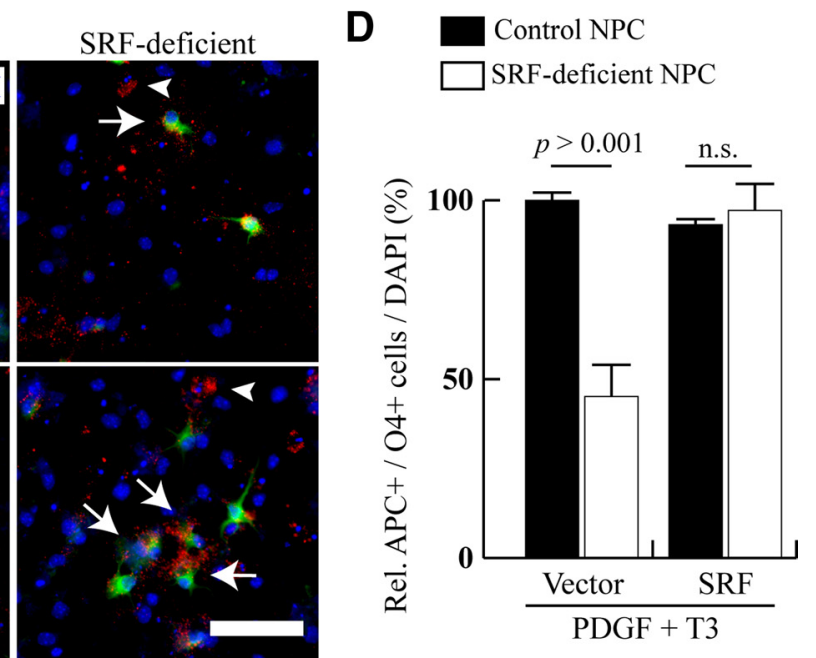

Figure 7. Reintroduction of wild-type SRF rescues glial specification defects. $\boldsymbol{A}$, Control and SRF-deficient NPCs were harvested from P0.5 brains and were infected with MSCV-SRF or with MSCV as control. NPCs were induced for astrocyte differentiation using CNTF and LIF and immunostained for GFAP expression at 4 DIV. Scale bar, $25 \mu \mathrm{m}$. $\boldsymbol{B}$, Analysis of the percentage of astrocytes

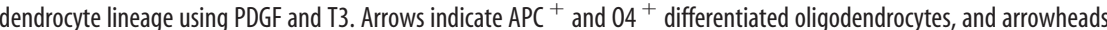
point to $04^{+}$late OPCS (4 DIV). Scale bar, $25 \mu \mathrm{m}$. D, Quantification shows that SRF expression does not augment oligodendrocyte differentiation in control NPCs but completely rescues differentiation deficits of SRF-deficient NPCS.

study, we found that mice with conditional deletion of SRF in NPCs (Srf-Nestin-cKO) exhibit deficits in astrocytes and oligodendrocyte specification in the brain. In contrast, SRF deletion in neurons (Srf-NEX-cKO) does not affect astrocyte development, suggesting a cell-autonomous role for SRF in astrocyte specification. Cultured SRF-deficient NPCs do not display any defects in proliferation or exhibit increased apoptosis. As observed in vivo, SRF-deficient NPCs were unable to properly differentiate into astrocytes and oligodendrocytes in response to lineage-specific differentiation signals. Thus, our study identifies a previously unknown cell-intrinsic role for SRF in glial cell-fate specification in the brain.

SRF deletion in Srf-Nestin-cKO resulted in loss of $\sim 40-60 \%$ astrocytes and oligodendrocytes in vivo. The Srf-Nestin-cKO mice also exhibited neonatal hemorrhage beginning at $\sim 12-16 \mathrm{~h}$ after birth and exhibited lethality soon after. The hemorrhagic phenotype could be attributable to reduced astrocytes, which are an essential component of the blood-brain barrier (Janzer and 
A

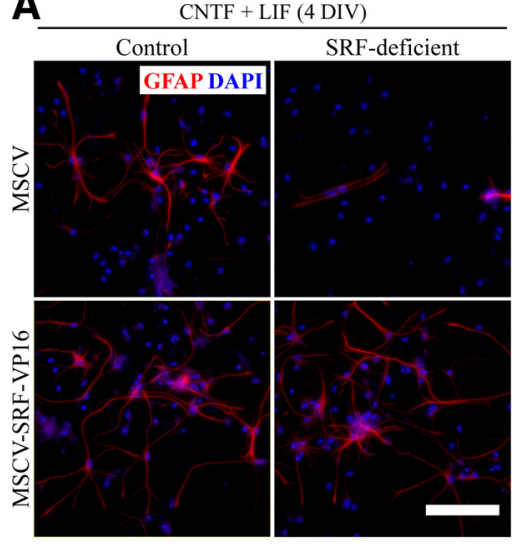

B

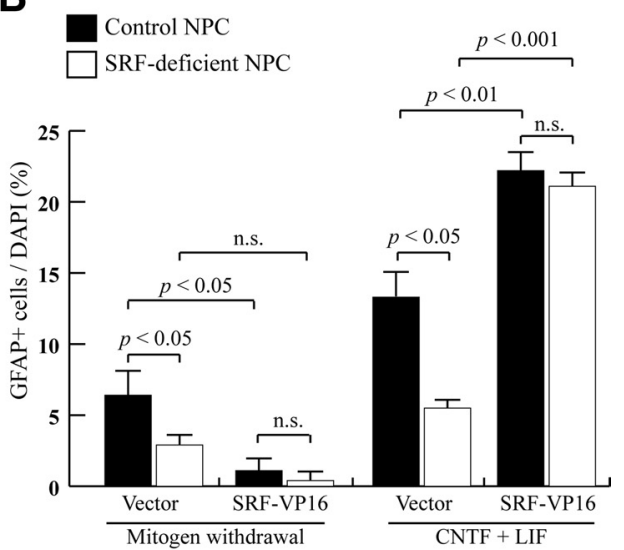

C

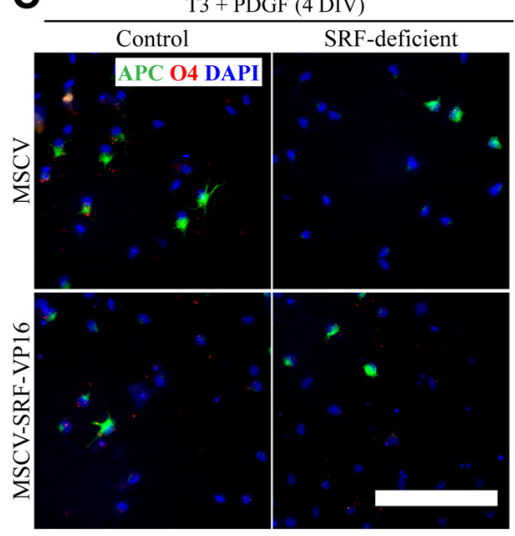

D

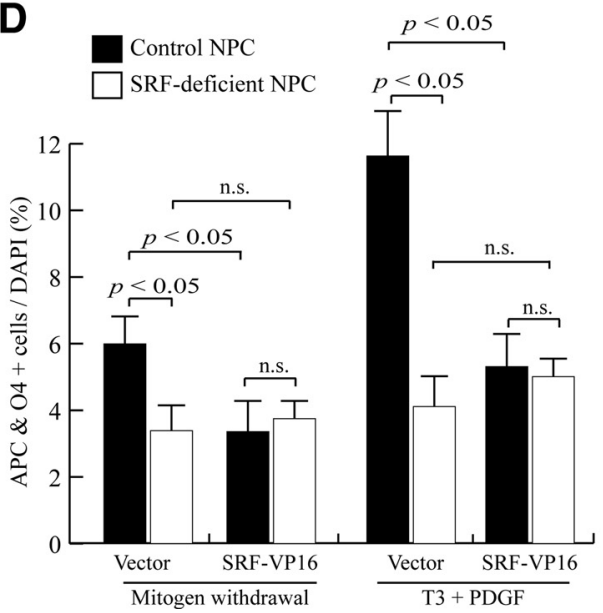

Figure 8. Constitutively active SRF is insufficient for glial specification but potentiates ligand-induced astrocyte differentiation. $\boldsymbol{A}$, Control and SRF-deficient NPCS were transduced with either empty MSCV or MSCV-SRF-VP16 virus. Three days after viral infection, NPCs were induced for astrocyte differentiation after mitogen withdrawal (representative images not shown) or with CNTF and LIF. Scale bar, $50 \mu \mathrm{m}$. B, Quantification of GFAP ${ }^{+}$astrocytes in $\boldsymbol{A}$ shows that, in the absence of mitogens, SRF-VP16 expression was slightly inhibitory to astrocyte specification. However, in the presence of LIF and CNTF, SRF-VP16 potentiated astrocyte differentiation of both control and SRF-deficient NPCS $(n=3)$. C, Oligodendrocyte differentiation of control and SRFdeficient NPCs after infection with either empty MSCV or MSCV-SRF-VP16 virus. NPCs were allowed to differentiate after mitogen withdrawal (representative images not shown) or were enriched for oligodendrocytes using $\mathrm{T} 3$ and PDGF. Differentiated oligodendrocytes were identified by $\mathrm{APC}^{+} / \mathrm{O4}^{+}$double immunoreactivity. Scale bar, $50 \mu \mathrm{m}$. D, Quantification of $\boldsymbol{C}$ indicates that SRF-VP16 is not sufficient to induce oligodendrocyte specification in the absence of pro-oligodendrocyte factors and inhibits oligodendrocyte differentiation in the presence of T3 and PDGF $(n=3)$.

Raff, 1987). Although not reported by several studies that have used the Nestin-Cre transgenic mouse line used in this study, it is also likely that there is leaky expression of Cre recombinase in endothelial cells. Because SRF has been shown to be important for vascular development (Franco et al., 2008), SRF deletion in endothelial cells could also compromise the integrity of the blood-brain barrier, resulting in hemorrhage. Future work will determine whether the hemorrhage is attributable to deficits in astrocyte numbers or vascular integrity or both.

Similar to the in vivo observations, SRF-deficient NPCs also exhibited a failure to generate astrocytes and oligodendrocytes when induced to differentiate in vitro. This could reflect a likely delay in glial specification, which is difficult to assess in SrfNestin-cKO mice because they exhibit neonatal lethality. However, we found that differentiation of SRF-deficient NPCs for longer periods (until $12 \mathrm{~d}$ ) in culture did not yield more astrocytes or oligodendrocytes, suggesting that a delay in specification is unlikely to be the underlying cause of the glial deficits in Srf-Nestin-cKO mice (our unpublished observations). Another possibility is that SRF is

required for specification of a particular glial-restricted precursor cell subpopulation or within a particular subpopulation for glial differentiation. A population of glialrestricted precursor cells that can generate both astrocytes and oligodendrocytes express the surface antigen A2B5 (Rao and Mayer-Proschel, 1997; Liu and Rao, 2004; Lin and Goldman, 2009). Recent studies have shown that astrocytes can be generated from more than one precursor cell type (Liu et al., 2004; Lin and Goldman, 2009; Cai et al., 2012). Future studies will aim to identify these precursor subpopulations in the brains of Srf-Nestin-cKO mice and study their capacity to generate astrocyte and oligodendrocytes in the absence of SRF.

Recent observations have shown that SRF-deficient neurons affect maturation of oligodendrocyte precursors in a non-cellautonomous manner (Stritt et al., 2009). In the reported Srf mutant mice, widespread SRF loss in late-embryonic forebrain neurons caused deficits in tangential neuronal migration, leading to cell accumulation in the subventricular zone (Alberti et al., 2005). This led to massive apoptosis and consequently triggered an increase in astrocytes postnatally possibly indicative of reactive astrogliosis (Alberti et al., 2005; Stritt et al., 2009). We found that SRF ablation in developing glutamatergic neurons of the neocortex and hippocampus in Srf-NEXcKO mice did not cause cell death or affect astrocyte differentiation even at 3 months of age. However, SRF loss in NPCs alone caused a significant reduction in astrocytes both in vivo and in vitro. Therefore, neuronal loss of SRF does not appear to have any effect on astrocyte specification and development.

Our findings suggest that SRF is required within NPCs to regulate oligodendrocyte specification. In addition, expression of constitutively active SRF-VP16 in NPCs inhibited oligodendrocyte specification in vitro. This observation is consistent with recent findings in which SRF-deficient neurons were shown to inhibit oligodendrocyte maturation in a paracrine manner via secretion of CTGF (Stritt et al., 2009). This study also showed that expression of SRF-VP16 in neurons inhibited maturation of neighboring oligodendrocytes in vitro. SRF-VP16 has not been shown to be subjected to the same regulatory mechanisms that modulate endogenous SRF activity. Therefore, it is likely that SRF-VP16 expression in NPCs also results in expression of CTGF, which could inhibit oligodendrocyte differentiation in an autocrine manner.

Interestingly, SRF-VP16 appeared to have an inhibitory effect on astrocyte specification in the absence of pro-astrocytic stimuli. However, in contrast to that observed for oligodendrocyte differentiation, SRF-VP16 expression resulted in $>40 \%$ increase in astrocyte differentiation in the presence of pro-astrocytic ligands. One likely explanation is that SRF-VP16 results in the upregulation of expression, within NPCs, of receptors and/or intracellular 
signaling proteins that are critical for astrocyte specification and in the presence of appropriate extracellular stimuli this causes a potentiated response and subsequent increase in astrocyte differentiation. Future work will aim to identify the SRF target genes in NPCs that are important for astrocyte and oligodendrocyte specification. Together, our observations strongly suggest that SRF plays a cell-intrinsic role in NPCs to regulate astrocyte and oligodendrocyte specification in the brain.

\section{References}

Ahmed S (2009) The culture of neural stem cells. J Cell Biochem 106:1-6. Alberta JA, Park SK, Mora J, Yuk D, Pawlitzky I, Iannarelli P, Vartanian T, Stiles CD, Rowitch DH (2001) Sonic hedgehog is required during an early phase of oligodendrocyte development in mammalian brain. Mol Cell Neurosci 18:434-441.

Alberti S, Krause SM, Kretz O, Philippar U, Lemberger T, Casanova E, Wiebel FF, Schwarz H, Frotscher M, Schütz G, Nordheim A (2005) Neuronal migration in the murine rostral migratory stream requires serum response factor. Proc Natl Acad Sci U S A 102:6148-6153.

Almazan G, Honegger P, Matthieu JM (1985) Triiodothyronine stimulation of oligodendroglial differentiation and myelination. A developmental study. Dev Neurosci 7:45-54.

Barnabé-Heider F, Wasylnka JA, Fernandes KJ, Porsche C, Sendtner M, Kaplan DR, Miller FD (2005) Evidence that embryonic neurons regulate the onset of cortical gliogenesis via cardiotrophin-1. Neuron 48:253-265.

Barres BA (2008) The mystery and magic of glia: a perspective on their roles in health and disease. Neuron 60:430-440.

Bonni A, Sun Y, Nadal-Vicens M, Bhatt A, Frank DA, Rozovsky I, Stahl N, Yancopoulos GD, Greenberg ME (1997) Regulation of gliogenesis in the central nervous system by the JAK-STAT signaling pathway. Science 278:477-483.

Cahoy JD, Emery B, Kaushal A, Foo LC, Zamanian JL, Christopherson KS, Xing Y, Lubischer JL, Krieg PA, Krupenko SA, Thompson WJ, Barres BA (2008) A transcriptome database for astrocytes, neurons, and oligodendrocytes: a new resource for understanding brain development and function. J Neurosci 28:264-278.

Cai N, Kurachi M, Shibasaki K, Okano-Uchida T, Ishizaki Y (2012) CD44positive cells are candidates for astrocyte precursor cells in developing mouse cerebellum. Cerebellum 11:181-193.

Dasgupta B, Gutmann DH (2005) Neurofibromin regulates neural stem cell proliferation, survival, and astroglial differentiation in vitro and in vivo. J Neurosci 25:5584-5594.

Deneen B, Ho R, Lukaszewicz A, Hochstim CJ, Gronostajski RM, Anderson DJ (2006) The transcription factor NFIA controls the onset of gliogenesis in the developing spinal cord. Neuron 52:953-968.

Emery B (2010) Regulation of oligodendrocyte differentiation and myelination. Science 330:779-782.

Etkin A, Alarcón JM, Weisberg SP, Touzani K, Huang YY, Nordheim A, Kandel ER (2006) A role in learning for SRF: deletion in the adult forebrain disrupts LTD and the formation of an immediate memory of a novel context. Neuron 50:127-143.

Fancy SP, Harrington EP, Yuen TJ, Silbereis JC, Zhao C, Baranzini SE, Bruce CC, Otero JJ, Huang EJ, Nusse R, Franklin RJ, Rowitch DH (2011) Axin2 as regulatory and therapeutic target in newborn brain injury and remyelination. Nat Neurosci 14:1009-1016.

Franco CA, Mericskay M, Parlakian A, Gary-Bobo G, Gao-Li J, Paulin D, Gustafsson E, Li Z (2008) Serum response factor is required for sprouting angiogenesis and vascular integrity. Dev Cell 15:448-461.

Freeman MR (2010) Specification and morphogenesis of astrocytes. Science 330:774-778.

Fu H, Cai J, Clevers H, Fast E, Gray S, Greenberg R, Jain MK, Ma Q, Qiu M, Rowitch DH, Taylor CM, Stiles CD (2009) A genome-wide screen for spatially restricted expression patterns identifies transcription factors that regulate glial development. J Neurosci 29:11399-11408.

Gaiano N, Fishell G (2002) The role of notch in promoting glial and neural stem cell fates. Annu Rev Neurosci 25:471-490.

Gard AL, Burrell MR, Pfeiffer SE, Rudge JS, Williams WC 2nd (1995) Astroglial control of oligodendrocyte survival mediated by PDGF and leukemia inhibitory factor-like protein. Development 121:2187-2197.

Goebbels S, Bormuth I, Bode U, Hermanson O, Schwab MH, Nave KA
(2006) Genetic targeting of principal neurons in neocortex and hippocampus of NEX-Cre mice. Genesis 44:611-621.

Grandbarbe L, Bouissac J, Rand M, Hrabé de Angelis M, Artavanis-Tsakonas S, Mohier E (2003) Delta-Notch signaling controls the generation of neurons/glia from neural stem cells in a stepwise process. Development 130:1391-1402.

He Y, Dupree J, Wang J, Sandoval J, Li J, Liu H, Shi Y, Nave KA, CasacciaBonnefil P (2007) The transcription factor Yin Yang 1 is essential for oligodendrocyte progenitor differentiation. Neuron 55:217-230.

Hegedus B, Dasgupta B, Shin JE, Emnett RJ, Hart-Mahon EK, Elghazi L, Bernal-Mizrachi E, Gutmann DH (2007) Neurofibromatosis-1 regulates neuronal and glial cell differentiation from neuroglial progenitors in vivo by both cAMP- and Ras-dependent mechanisms. Cell Stem Cell $1: 443-457$.

Hirano A (1968) A confirmation of the oligodendroglial origin of myelin in the adult rat. J Cell Biol 38:637-640.

Janzer RC, Raff MC (1987) Astrocytes induce blood-brain barrier properties in endothelial cells. Nature 325:253-257.

Johansen FE, Prywes R (1994) Two pathways for serum regulation of the $\mathrm{c}$-fos serum response element require specific sequence elements and a minimal domain of serum response factor. Mol Cell Biol 14:5920-5928.

Johe KK, Hazel TG, Muller T, Dugich-Djordjevic MM, McKay RD (1996) Single factors direct the differentiation of stem cells from the fetal and adult central nervous system. Genes Dev 10:3129-3140.

Johnson AW, Crombag HS, Smith DR, Ramanan N (2011) Effects of serum response factor (SRF) deletion on conditioned reinforcement. Behav Brain Res 220:312-318.

Kahn MA, De Vellis J (1994) Regulation of an oligodendrocyte progenitor cell line by the interleukin-6 family of cytokines. Glia 12:87-98.

Knöll B, Kretz O, Fiedler C, Alberti S, Schütz G, Frotscher M, Nordheim A (2006) Serum response factor controls neuronal circuit assembly in the hippocampus. Nat Neurosci 9:195-204.

Lee JC, Mayer-Proschel M, Rao MS (2000) Gliogenesis in the central nervous system. Glia 30:105-121.

Lin G, Goldman JE (2009) An FGF-responsive astrocyte precursor isolated from the neonatal forebrain. Glia 57:592-603.

Liu Y, Rao MS (2004) Glial progenitors in the CNS and possible lineage relationships among them. Biol Cell 96:279-290.

Liu Y, Han SS, Wu Y, Tuohy TM, Xue H, Cai J, Back SA, Sherman LS, Fischer I, Rao MS (2004) CD44 expression identifies astrocyte-restricted precursor cells. Dev Biol 276:31-46.

Lobsiger CS, Cleveland DW (2007) Glial cells as intrinsic components of non-cell-autonomous neurodegenerative disease. Nat Neurosci 10:1355-1360.

Lu PP, Ramanan N (2011) Serum response factor is required for cortical axon growth but dispensable for neurogenesis and neocortical lamination. J Neurosci 31:16651-16664.

Lu QR, Yuk D, Alberta JA, Zhu Z, Pawlitzky I, Chan J, McMahon AP, Stiles CD, Rowitch DH (2000) Sonic hedgehog-regulated oligodendrocyte lineage genes encoding bHLH proteins in the mammalian central nervous system. Neuron 25:317-329.

Lu QR, Cai L, Rowitch D, Cepko CL, Stiles CD (2001) Ectopic expression of Olig1 promotes oligodendrocyte formation and reduces neuronal survival in developing mouse cortex. Nat Neurosci 4:973-974.

Lu QR, Sun T, Zhu Z, Ma N, Garcia M, Stiles CD, Rowitch DH (2002) Common developmental requirement for Olig function indicates a motor neuron/oligodendrocyte connection. Cell 109:75-86.

März P, Heese K, Dimitriades-Schmutz B, Rose-John S, Otten U (1999) Role of interleukin- 6 and soluble IL-6 receptor in region-specific induction of astrocytic differentiation and neurotrophin expression. Glia 26:191-200.

McKinnon RD, Matsui T, Dubois-Dalcq M, Aaronson SA (1990) FGF modulates the PDGF-driven pathway of oligodendrocyte development. Neuron 5:603-614.

Miano JM, Ramanan N, Georger MA, de Mesy Bentley KL, Emerson RL, Balza RO Jr, Xiao Q, Weiler H, Ginty DD, Misra RP (2004) Restricted inactivation of serum response factor to the cardiovascular system. Proc Nat Acad Sci U S A 101:17132-17137.

Miller RH (1996) Oligodendrocyte origins. Trends Neurosci 19:92-96.

Morrison SJ, Perez SE, Qiao Z, Verdi JM, Hicks C, Weinmaster G, Anderson DJ (2000) Transient Notch activation initiates an irreversible switch 
from neurogenesis to gliogenesis by neural crest stem cells. Cell 101:499-510.

Muroyama Y, Fujiwara Y, Orkin SH, Rowitch DH (2005) Specification of astrocytes by bHLH protein SCL in a restricted region of the neural tube. Nature 438:360-363.

Nakashima K, Yanagisawa M, Arakawa H, Kimura N, Hisatsune T, Kawabata M, Miyazono K, Taga T (1999) Synergistic signaling in fetal brain by STAT3-Smad1 complex bridged by p300. Science 284:479-482.

Nakashima K, Takizawa T, Ochiai W, Yanagisawa M, Hisatsune T, Nakafuku M, Miyazono K, Kishimoto T, Kageyama R, Taga T (2001) BMP2mediated alteration in the developmental pathway of fetal mouse brain cells from neurogenesis to astrocytogenesis. Proc Natl Acad Sci U S A 98:5868-5873.

Namihira M, Kohyama J, Semi K, Sanosaka T, Deneen B, Taga T, Nakashima K (2009) Committed neuronal precursors confer astrocytic potential on residual neural precursor cells. Dev Cell 16:245-255.

Niu Z, Yu W, Zhang SX, Barron M, Belaguli NS, Schneider MD, Parmacek M, Nordheim A, Schwartz RJ (2005) Conditional mutagenesis of the murine serum response factor gene blocks cardiogenesis and the transcription of downstream gene targets. J Biol Chem 280:32531-32538.

Oberheim NA, Tian GF, Han X, Peng W, Takano T, Ransom B, Nedergaard M (2008) Loss of astrocytic domain organization in the epileptic brain. J Neurosci 28:3264-3276.

Ochiai W, Yanagisawa M, Takizawa T, Nakashima K, Taga T (2001) Astrocyte differentiation of fetal neuroepithelial cells involving cardiotrophin1-induced activation of STAT3. Cytokine 14:264-271.

Okano H, Temple S (2009) Cell types to order: temporal specification of CNS stem cells. Curr Opin Neurobiol 19:112-119.

Parlakian A, Tuil D, Hamard G, Tavernier G, Hentzen D, Concordet JP, Paulin D, Li Z, Daegelen D (2004) Targeted inactivation of serum response factor in the developing heart results in myocardial defects and embryonic lethality. Mol Cell Biol 24:5281-5289.

Rajan P, McKay RD (1998) Multiple routes to astrocytic differentiation in the CNS. J Neurosci 18:3620-3629.

Ramanan N, Shen Y, Sarsfield S, Lemberger T, Schütz G, Linden DJ, Ginty DD (2005) SRF mediates activity-induced gene expression and synaptic plasticity but not neuronal viability. Nat Neurosci 8:759-767.

Rao MS (1999) Multipotent and restricted precursors in the central nervous system. Anat Rec 257:137-148.

Rao MS, Mayer-Proschel M (1997) Glial-restricted precursors are derived from multipotent neuroepithelial stem cells. Dev Biol 188:48-63.

Robinson S, Miller R (1996) Environmental enhancement of growth factormediated oligodendrocyte precursor proliferation. Mol Cell Neurosci $8: 38-52$.

Sandbo N, Kregel S, Taurin S, Bhorade S, Dulin NO (2009) Critical role of serum response factor in pulmonary myofibroblast differentiation induced by TGF-beta. Am J Respir Cell Mol Biol 41:332-338.

Sauvageot CM, Stiles CD (2002) Molecular mechanisms controlling cortical gliogenesis. Curr Opin Neurobiol 12:244-249.

Schratt G, Philippar U, Berger J, Schwarz H, Heidenreich O, Nordheim A (2002) Serum response factor is crucial for actin cytoskeletal organiza- tion and focal adhesion assembly in embryonic stem cells. J Cell Biol 156:737-750.

Sohn J, Natale J, Chew LJ, Belachew S, Cheng Y, Aguirre A, Lytle J, NaitOumesmar B, Kerninon C, Kanai-Azuma M, Kanai Y, Gallo V (2006) Identification of Sox17 as a transcription factor that regulates oligodendrocyte development. J Neurosci 26:9722-9735.

Stern S, Debre E, Stritt C, Berger J, Posern G, Knöll B (2009) A nuclear actin function regulates neuronal motility by serum response factor-dependent gene transcription. J Neurosci 29:4512-4518.

Stolt CC, Rehberg S, Ader M, Lommes P, Riethmacher D, Schachner M, Bartsch U, Wegner M (2002) Terminal differentiation of myelinforming oligodendrocytes depends on the transcription factor Sox10. Genes Dev 16:165-170.

Stolt CC, Lommes P, Sock E, Chaboissier MC, Schedl A, Wegner M (2003) The Sox 9 transcription factor determines glial fate choice in the developing spinal cord. Genes Dev 17:1677-1689.

Stritt C, Stern S, Harting K, Manke T, Sinske D, Schwarz H, Vingron M, Nordheim A, Knöll B (2009) Paracrine control of oligodendrocyte differentiation by SRF-directed neuronal gene expression. Nat Neurosci 12:418-427.

Takizawa T, Yanagisawa M, Ochiai W, Yasukawa K, Ishiguro T, Nakashima K, Taga T (2001) Directly linked soluble IL-6 receptor-IL-6 fusion protein induces astrocyte differentiation from neuroepithelial cells via activation of STAT3. Cytokine 13:272-279.

Tanigaki K, Nogaki F, Takahashi J, Tashiro K, Kurooka H, Honjo T (2001) Notch 1 and Notch 3 instructively restrict bFGF-responsive multipotent neural progenitor cells to an astroglial fate. Neuron 29:45-55.

Tekki-Kessaris N, Woodruff R, Hall AC, Gaffield W, Kimura S, Stiles CD, Rowitch DH, Richardson WD (2001) Hedgehog-dependent oligodendrocyte lineage specification in the telencephalon. Development 128:2545-2554.

Tronche F, Kellendonk C, Kretz O, Gass P, Anlag K, Orban PC, Bock R, Klein R, Schutz G (1999) Disruption of the glucocorticoid receptor gene in the nervous system results in reduced anxiety. Nat Genet 23:99-103.

Verdoni AM, Ikeda S, Ikeda A (2010) Serum response factor is essential for the proper development of skin epithelium. Mamm Genome 21:64-76.

Woodruff RH, Tekki-Kessaris N, Stiles CD, Rowitch DH, Richardson WD (2001) Oligodendrocyte development in the spinal cord and telencephalon: common themes and new perspectives. Int J Dev Neurosci 19:379-385

Yanagisawa M, Nakashima K, Takizawa T, Ochiai W, Arakawa H, Taga T (2001) Signaling crosstalk underlying synergistic induction of astrocyte differentiation by BMPs and IL-6 family of cytokines. FEBS Lett 489:139-143.

Zhou Q, Anderson DJ (2002) The bHLH transcription factors OLIG2 and OLIG1 couple neuronal and glial subtype specification. Cell 109:61-73.

Zhou Q, Wang S, Anderson DJ (2000) Identification of a novel family of oligodendrocyte lineage-specific basic helix-loop-helix transcription factors. Neuron 25:331-343.

Zhou Q, Choi G, Anderson DJ (2001) The bHLH transcription factor Olig2 promotes oligodendrocyte differentiation in collaboration with $\mathrm{Nkx} 2.2$. Neuron 31:791-807. 